\title{
UNELASSIFE
}

\section{S8DR CORE PERFORMANCE}

EVALUATION

(Title Unclassified)

AEC Research and Development Report

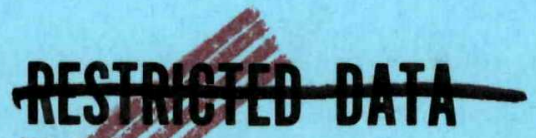

This document confains restricted data as defined in the Atomic Energy Act of 1954. Its transmittal or the disclosure or its contents in any manner to an unauthorifed person is prohibited.

This document contains Confidential-Restricted Data relating to civilian applications of afomic energy.
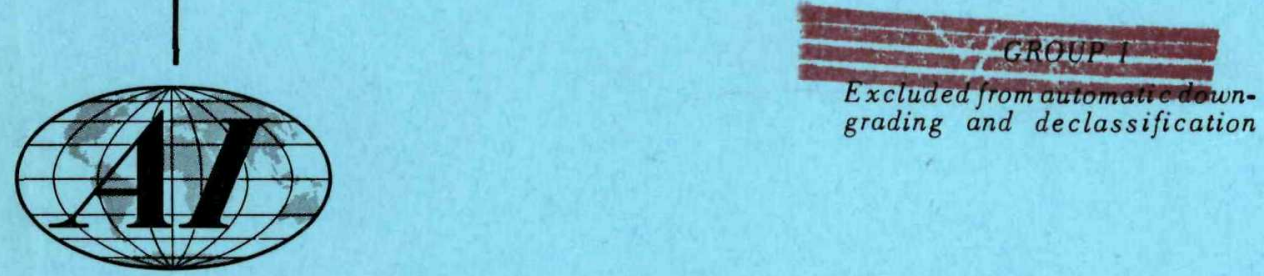

\section{ATOMICS INTERNATIONAL}

A DIVISION OF NORTH AMERICAN AVIATION, INC. WMLASSFED

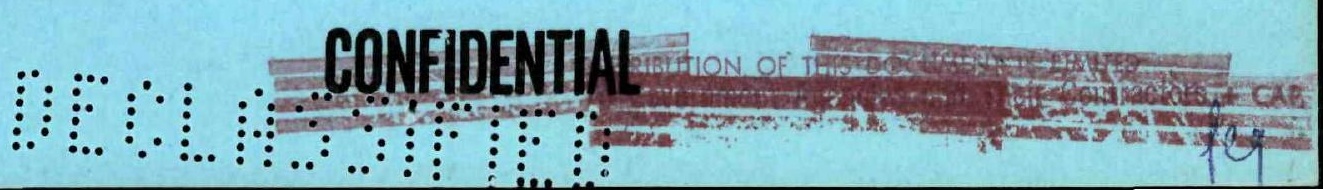




\section{DISCLAIMER}

This report was prepared as an account of work sponsored by an agency of the United States Government. Neither the United States Government nor any agency Thereof, nor any of their employees, makes any warranty, express or implied, or assumes any legal liability or responsibility for the accuracy, completeness, or usefulness of any information, apparatus, product, or process disclosed, or represents that its use would not infringe privately owned rights. Reference herein to any specific commercial product, process, or service by trade name, trademark, manufacturer, or otherwise does not necessarily constitute or imply its endorsement, recommendation, or favoring by the United States Government or any agency thereof. The views and opinions of authors expressed herein do not necessarily state or reflect those of the United States Government or any agency thereof. 


\section{DISCLAIMER}

Portions of this document may be illegible in electronic image products. Images are produced from the best available original document. 


\section{LEGAL NOTICE}

This report was prepared as an account of Government sponsored work. Neither the United States, nor the Commission, nor any person acting on behalf of the Commission:

A. Makes any warranty or representation, express or implied, with respect to the accuracy, completeness, or usefulness of the information contained in this report, or that the use of any information, apparatus, method, or process disclosed in this report may not infringe privately owned rights; or

B. Assumes any liabilities with respect to the use of, or for damages resulting from the use of information, apparatus, method, or process disclosed in this report.

As used in the above, "person acting on behalf of the Commission" includes ony employee or contractor of the Commission, or employee of such contractor, to the extent that such employee or contractor of the Commission, or employee of such contractor pre. pares, disseminates, or provides access to, any information pursuant to his employment or contract with the Commission, or his employment with such contractor.

Printed in USA

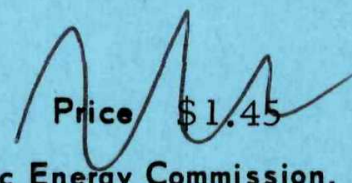

Available from the

U.S. Atomic Energy Commission,

Division of Technical Information Extension,

P. 0. Box 62

Oak Ridge, Tennessee.

Please direct to the same address inquiries covering the procurement of other clossified AEC reports.

\section{CONFIDENTIML}




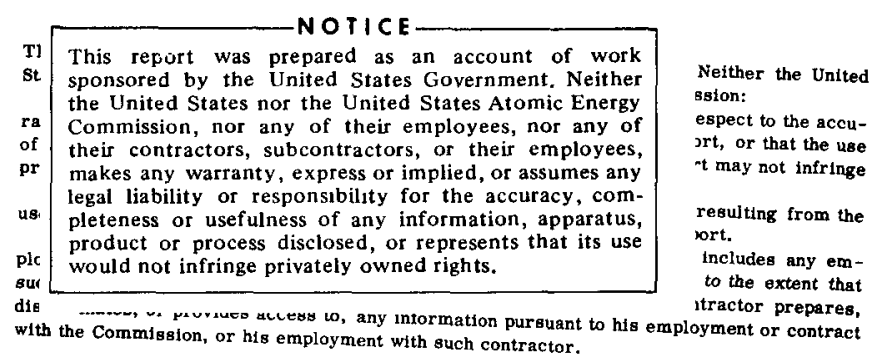

S8DR CORE PERFORMANCE

EVALUATION

(Title Unclassified)
NAA-SR- 12482

SNAP REACTOR, SNAP PROGRAM $M-3679$ (51st Ed.)

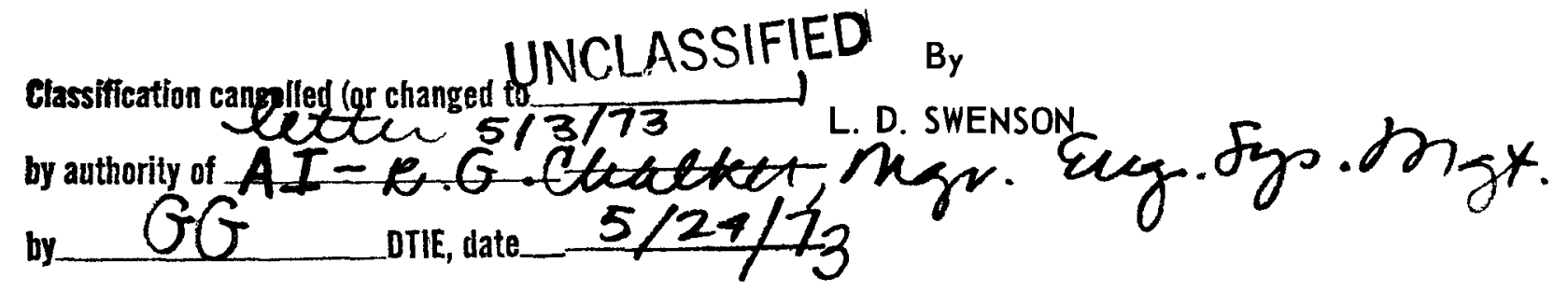

Exempt from CCRP Re-review Requirements

(per 7/22/82 Duff/Caudle memorandum) 3/4/o4

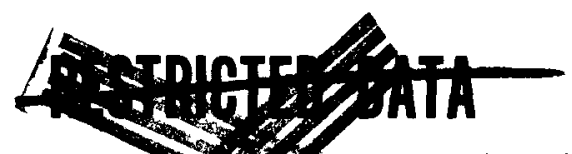

This document confay defata os defined in the Aromic Energy of the disclosure of its, in to an unauthorized per

This documbin Confidential-Restricted Dato relating to civc. ap aplications of atomic energy.

\section{ATOMICS INTERNATIONAL}

A DIVISION OF NORTH AMERICAN AVIATION, INC. P.O. BOX 309 CANOGA PARK, CALIFORNIA 


\section{DISTRIBUTION}

\section{SYSTEMS FOR NUCLEAR AUXILIARY POWER (SNAP)-REACTOR SNAP PROGRAM $M-3679$ (5 lst Ed.)}

No, of

Copies

AEC Albuquerque Operations Office

AEC California Patent Group

AEC Chicago Patent Group

AEC New York Operations Office

AEC Oak Ridge Operations Office AEC Patent Office

Aerojet-General Corporation (NASA)

Aerojet-General Corporation,

Sacramento

Aerojet-General Corporation,

San Ramon (NASA)

Aerospace Corporation

Air Force Aeronautical Systems

Division

Air Force Foreign Technology Division

Air Force Headquarters

Air Force Weapons Laboratory

Air University Library

Argonne National Laboratory

Army Reactors Field Group

Army White Sands Missile Range

ARO, Inc.

Battelle Memorial Institute

Battelle-Northwest

Bendix Corporation (NASA)

Brookhaven National Laboratory

Central Intelligence Agency

Director of Defense Research and

Engineering

Du Pont Company, Aiken

Du Pont Company, Wilmington

Electro-Optical Systems, Inc.

General Atomic Division

General Dynamics/Fort Worth

General Electric Company, Cincinnati (AEC)

General Electric Company (FPD)

General Electric Company MSVD (AEC)

General Electric Company, San Jose

Institute for Defense Analyses

J et Propulsion Laboratory (NASA)

Johns Hopkins University (APL)

Lawrence Radiation Laboratory,

Livermore

Lockheed-Georgia Company

Los Alamos Scientific Laboratory
Martin Company

Martin Company, Denver

Minnesota Mining and Manufacturing Company

Mound Laboratory

NASA Goddard Space Flight Center

NASA Langley Research Center

NASA Lewis Research Center

NASA Manned Spacecraft Center

NASA Marshall Space Flight Center

NASA, Washington

National Reactor Testing Station (INC)

Navy Air Development Center

Navy Marine Engineering Laboratory

Navy Office of the Chief of Naval

Operations

Navy Ordnance Systems Command

Navy Radiological Defense Laboratory

Navy Research Laboratory

Navy Ship Systems Command

Headquarters

Oak Ridge National Laboratory (AEC)

Pratt and Whitney Aircraft Division (NASA)

Radio Corporation of America (NY)

Radio Corporation of America,

Cranbury

Rand Corporation

Republic Aviation Division

Sandia Corporation, Albuquerque (AEC)

Tracerlab, Richmond

TRW Systems

Westinghouse Electric Corporation, Lima

Westinghouse Electric Corporation, Lima (AF)

Westinghouse Electric Corporation (NASA)

Westinghouse Electric Corporation (WAL)

AEC Division of Technical Information Extension

AI Library (Includes 2 copies to CPAO, 2 copies to AEC, Washington,

2 copies to $S F O O)$
No. of Copies

1

NAA -SR - 12482

2 


\section{CONTENTS}

Abstract ........................... 7

I. Introduction $\ldots \ldots \ldots \ldots \ldots$

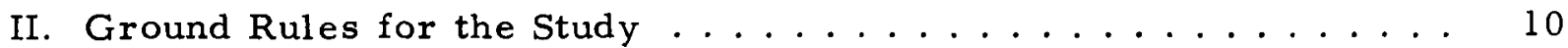

III. Independent Variables ..................... 13

IV . Dependent Variables..................... 15

A. Lifetime Limitations .................... 15

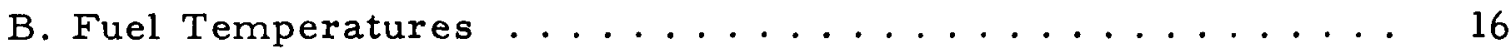

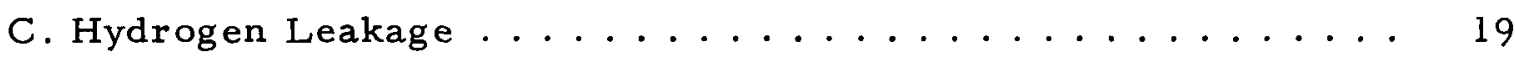

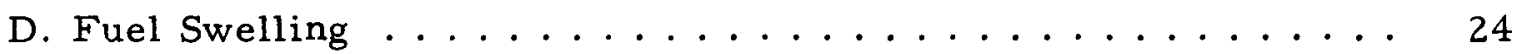

V. Calculational Methods ................... 27

A. Lifetime Calculations . . . . . . . . . . . . . 27

B. Temperature Calculations .................. 27

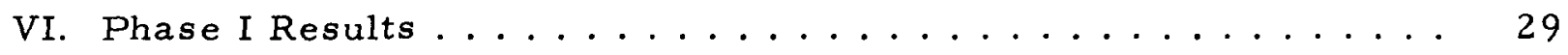

A. Ground Rules for Phase I .................. 29

B. Gas Gap Optimization . . . . . . . . . . . . . 30

1. Fuel Swelling Assumptions ................ 30

2. Coolant Flow Profile.................. 32

3. Other Factors Affecting Phase Change.......... 35

C. Reactivity Limits . . . . . . . . . . . . . . . . 41

D. Thermal Performance ................... 41

E. Stress Analysis ..................... 46

VII. Phase II Results. ....................... 51

A. Ground Rules for Phase II ................. 51

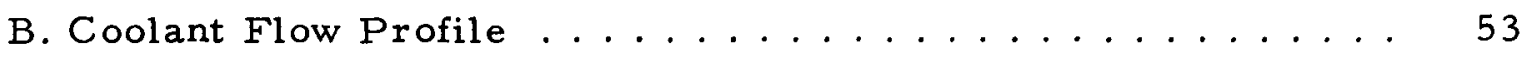

C. Gas Gap Optimization ...................... 56

D. Reactivity Limits. . . . . . . . . . . . . . . 59

E. Stress Analysis............................ 64

F. Statistical Analysis of Fuel-Cladding Contact . . . . . . . 67

VIII. Conclusions and Recommendations . . . . . . . . . . . 71

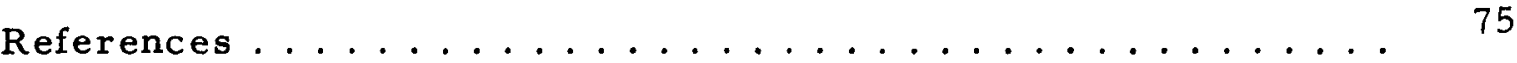

NAA -SR - 12482 


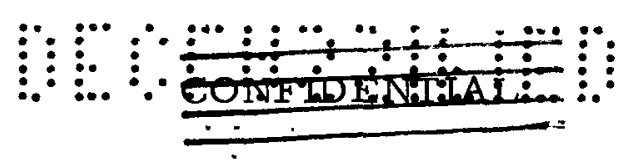

TABLES

Page

1. Distribution of Peak Fuel Temperature Uncertainties

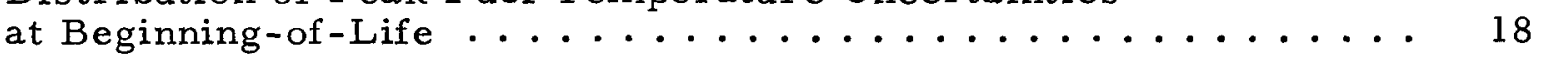

2. Distribution of Peak Fuel Temperature Uncertainties

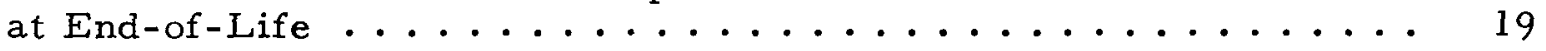

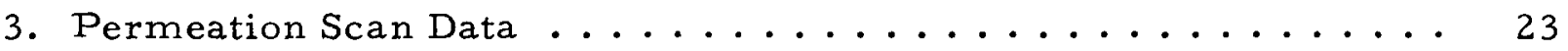

4. Time to Phase Change With Current S8DR Flow Profile ...... 36

5. Time to Phase Change in S8DR With Variable Axial

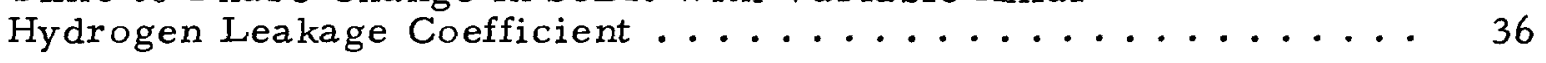

6. Time to Phase Change in S8DR With Uncertainty in the Hydrogen Leakage Coefficient ................... 37

7. Time to Phase Change in S8DR With Various Assumed

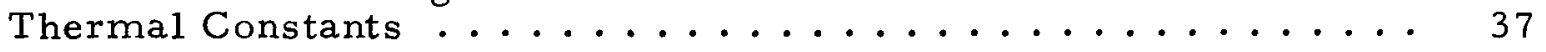

8. Time to Phase Change as a Function of Core Temperature Rise . . 39

9. Calculated Stress Safety Factors . . . . . . . . . . . . 48

10. Summary of Stress Combinations . . . . . . . . . . . 49

11. Minimum Core Vessel Wall Thickness ... . . . . . . . . . 52

12. S8DR Axial Gas Gap Selection ................... 59

13. S8DR Excess Reactivity 211 Elements, 5-1/8-in. Reflector,

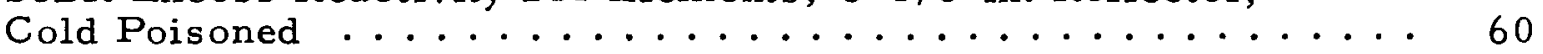

14. S8DR Excess Reactivity 207 Elements, 5-1/8-in. Reflector,

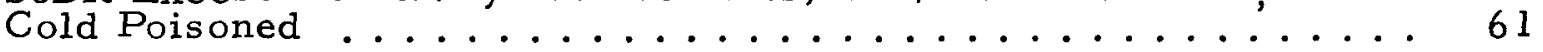

15. S8DR Reactivity $211-$ Element Cores ...............61

16. S8DR Reactivity Proposed Variably Spaced 207-Element Core . . 62

17. S8DR Stress Safety Factors .................... 66

18. Summary of Recommendations S8DR Fuel Element . . . . . . . 71

19. Summary of Recommendations S8DR Core ............. 71

\section{FIGURES}

1. Hydrogen Loss Rate Coefficient .................. 21

2. Temperature Cycles for S8DR Developmental Elements . . . . . 22

3. Diametral Growth vs Burnup for Intact S8ER Elements . . . . . . 24

4. Predicted Fuel Growth vs Burnup ................. 26

5. S8DR Lifetime vs Initial Gap (600 kwt, 211 -Element Core, $1300^{\circ} \mathrm{F}$ Outlet, Present Flow Profile) ................ 33

NAA-SR - 12482

4

CONEIDENTIAE 


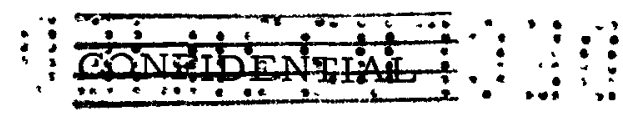

\section{FIGURES}

Page

6. S8DR Lifetime vs Initial Gap (450 kwt, 211 -Element Core, $1300^{\circ} \mathrm{F}$ Outlet, Present Flow Profile) ................ 33

7. S8DR Lifetime Studies Flow Profile Variation ........... 34

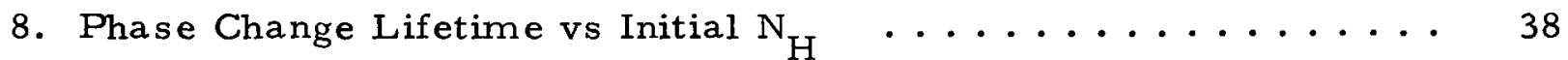

9. Hydrogen Content of As-Built S8DR Fuel ............... 38

10. Typical "Ring" Temperature Calculations . . . . . . . . . . . 42

11. Peak Fuel Temperatures for Variable Area Core . . . . . . . . 43

12. Flow Profile, Rod-Centered Core ................ 43

13. Temperature Distributions, S8DR Symmetric Fuel Rod . . . . . 44

14. Effect of Element Spacing on Temperature Distribution . . . . . . 44

15. Effect of Cladding Thickness on Temperature Distribution . . . . 44

16. Temperature Distributions for S8DR Asymmetric Fuel Rod . . . 45

17. Axial Stress Due to Circumferential Temperature Variation . . . 47

18. S8DR Peak Fuel Temperature Comparison (Beginning-of-Life) ... 55

19. S8DR Peak Fuel Temperature Comparison

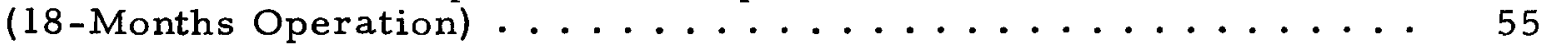

20. S8DR Maximum Cladding Temperature Comparison

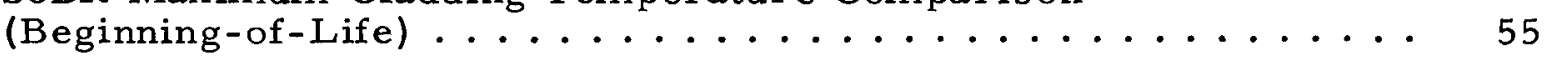

21. S8DR Maximum Cladding Temperature Comparison

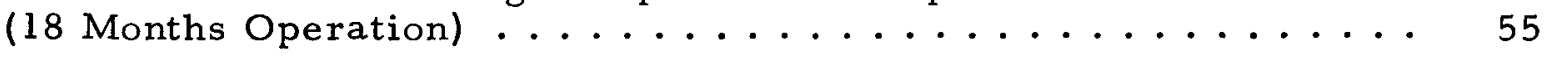

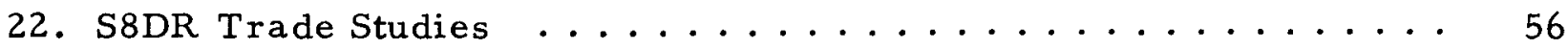

23. S8DR Lifetime vs Gap, 211 Elements, Current Baffle ...... 57

24. S8DR Lifetime vs Gap, 211 Elements, Cladding

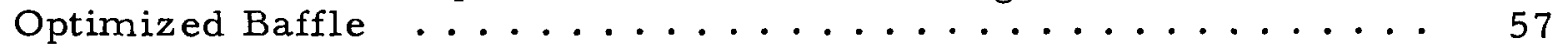

25. Predicted S8DR Reactivity Loss vs Time ............ 63

26. Lower End Cap Designs ........................ 65

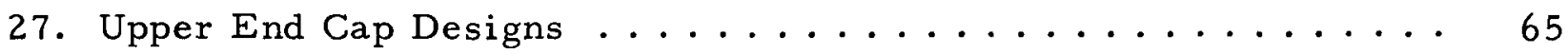

28. Creep Collapse Model ......................... 66

29. Preliminary S8DR Fuel Gap Statistical Study ........... . 69

30. Fuel-Cladding Contact Probability After 12,000-hr Operation ... 69

31. Fuel Growth Distribution ...................... 70

32. Modified S8DR Fuel Element Lower End Cap . . . . . . . . . 73

33. Original and New Reference Upper End Cap Designs . . . . . . 73

NAA-SR -12482

5

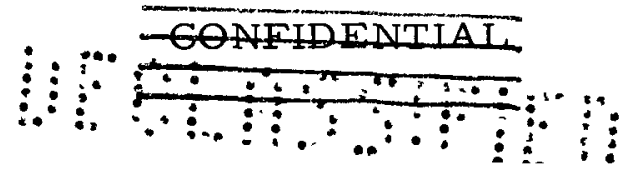




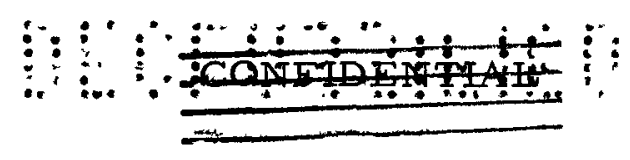

\section{ACKNOWLEDGMENT}

The author wishes to thank K. R. Birney, R. H. Tromel, A. W. Dalcher, and R. A. Johnson for their contributions to this report. Although the majority of their work had been previously published, it was considered desirable to abstract it and include it in this report so that a complete summary of the work involved in the trade studies might be available.

Specifically, thanks go to K. R. Birney for the fuel swelling correlations, his statistical treatment of the experimental fuel growth data, and his continuing effort in updating the LOAFER computer code. Special thanks also go to R. H. Tromel for the coolant flow optimization work, the detailed temperature calculations, and his work with TEMPR 8. A. W. Dalcher provided the majority of the stress calculations, and subsequent discussions with him proved most helpful in the preparation of this report. R. A. Johnson provided the majority of the writeup for the sections discussing the stress calculations. The work of these gentlemen, and their colleagues, has been plagiarized in order to provide the desired, comprehensive report. Special thanks also go to E. J. Donevan and W. J. Roberts for their review of this report and their helpful comments during its preparation.

NAA -SR - 12482

6 


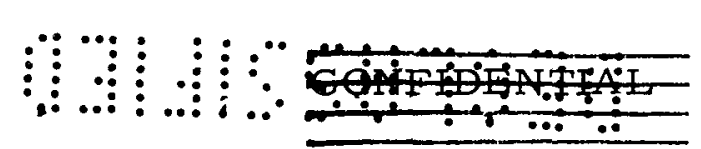

\section{ABSTRACT}

The SNAP 8 Developmental Reactor (S8DR)-formerly S8DS design was reviewed in order to incorporate information from the SNAP 8 Experimental Reactor ( $S 8 E R$ ) reactor operation and post-operation examination, information from the recent fuel capsule irradiations, and current information on the hydrogen leakage behavior of the fuel elements. The reactor trade studies associated with the final design specification for S8DR are detailed. The study is outlined in approximately chronological fashion and is divided into two separate phases. The recommendations resulting from the completed study follow.

1) Increase the axial fuel-to-cladding clearance to $0.240 \mathrm{in}$.

2) Reduce the fuel rod diameter by $0.001-$ in.

3) Retain the nominal 10-mil cladding thickness

4) Utilize a new fuel element upper end cap design

5) Modify the fuel element lower end cap design

6) Modify the fuel rod dimensions to accommodate the changes recommended in 4) and 5)

7) Retain the uniformly spaced, 211 fuel element core concept

8) Increase the minimum element-to-element spacing from 7.4 to $10 \mathrm{mils}$

9) Machine the core vessel ID to accommodate recommendation 8)

10) Reduce the system operating pressure to 35 psia

11) Modify the coolant flow profile through the core

12) Conduct hydraulic tests to verify the design changes necessary to achieve recommendation 11 ). 
आִ

BLANK 


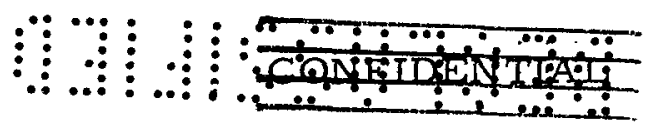

\section{INTRODUCTION}

The design of the nuclear reactor core for the S8DR, formerly S8DS, has been reexamined to allow incorporation of information gained from the S8ER test and of information which has only recently become available from fuel irradiation tests. Even though S8ER operated for $5.1 \times 10^{6} \mathrm{kwt}-\mathrm{hr}$ (500 days of operation of which 365 days were above $400 \mathrm{kwt}$ and at a rated outlet temperature of $1300^{\circ} \mathrm{F}$ ), thereby demonstrating the feasibility of the SNAP 8 concept, several unexpected things were observed during the experiment and the subsequent postoperation examination. The principal abnormalities were, (1) excessive fuel swelling, which ultimately caused, (2) fuel cladding failure (cracking) in the majority of the elements.

Since the reactor core design for S8DR was based on the data used to predict the operation of S8ER, it was necessary to reevaluate certain parts of the previous S8DR analysis in order to assure that the core design was adequate to meet the design requirements. The current study provides an optimization of the fuel-to-cladding gas gaps utilizing the data from the S8ER experiment and the fuel irradiation experiments. It also assesses the design performance margin of S8DR and recommends several design changes which will enhance the performance margin.

The study was performed in two phases. Phase I of the study compared the reference design 211 -element core with the use of 15-mil thick cladding and 199 fuel elements in the reference core vessel. Phase II of the study considered only the use of the nominal 10-mil cladding thickness with the option of increasing the element-to-element spacing by shaving the core vessel ID and using 207 fuel elements. The possibility of changing the coolant flow profile was considered in both phases of the study. Various off-design operational conditions and several sets of design assumptions were examined to determine the sensitivity of the diametral gap optimization to these perturbations. The axial fuel-to-cladding gas gap was also respecified based on the new fuel swelling data.

The analysis methods which were employed were essentially the same for both Phase I and Phase II of the study. The analysis techniques are discussed in the Sections III, IV, and V. Some differences exist between the models

NAA -SR - 12482

9

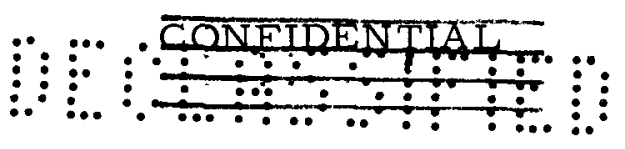


(notably, the thermal conductivity of the fuel material) used in the two phases of the study. While these differences may affect the magnitude of the results, the trends which are establishedareconsidered to be still valid and the final conclusions unaffected.

The general ground rules for the study are discussed in Section II. The differences in the ground rules which existed between Phase I and Phase II of the study are discussed separately in Sections VI and Section VII, respectively, which also detail the results of the two phases of the study. The conclusions and recommendations which resulted from the study are detailed in Section VIII. 


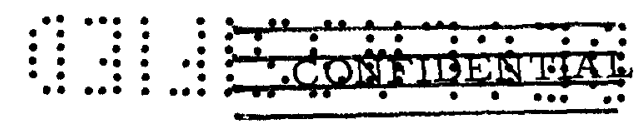

\section{GROUND RULES FOR THE STUDY}

The reactor optimization was performed within rather stringent ground rules since a large number of the components for the S8DR reactor system had already been manufactured and a complete redesign would have been uneconomical as well as unnecessary. The S8ER test had demonstrated the overall reliability of the reactor design.

The ground rules for the fuel-to-cladding gap optimization were similar for the two phases of the study. The fixed requirements which were common to both phases of the study are listed below. They specified that no change be made from the previously adopted specifications for S8DS for the following items.

1) Fuel material

2) Hydrogen content in the fuel

3) Fuel rod length

4) Burnable poison

5) Reactor core vessel external diameter

6) Reflector configuration.

The differences between Phase I and Phase II are given in the sections detailing the results of the respective phases of the study.

The fuel for S8DR had been manufactured and machined to the final specifications although it had not been clad. Perturbations to the fuel rod size we re to be kept to a minimum. The active fuel length was to be maintained at 16.825 in., while the fuel rod diameter was not to be greater than 0.530 in. However, the option to "shave" the rod diameter so that the fuel-to-cladding gas gap could be increased was allowed in this study. The hydrogen content of the fuel could conceivably have been changed, although it would have required rehydriding the fuel and repeating the final machining operation. There is insufficient performance data on rehydrided fuel to make this a desirable option. It was also decided to retain the currently developed prepoison material $\left(\mathrm{Sm}_{2} \mathrm{O}_{3}\right)$ and loading $(\$ 3.00)$, though a slower burning prepoison would have been more desirable because it would have reduced the control requirements.

NAA -SR- 12482

11

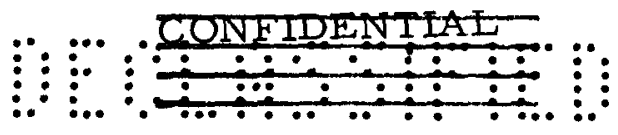


The core vessel outside diameter was retained at its previously specified size since the reflector had already been fabricated. Changing the core vessel size would have necessitated refabrication of the reflector assembly.

NAA - SR- 12482

12 


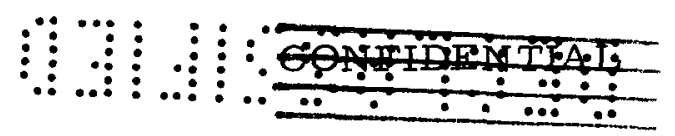

\section{INDEPENDENT VARIABLES}

The independent variables investigated in this study fell into the six main categories listed below.

1) Operating conditions (power level, outlet temperature, etc.)

2) Fuel-to-cladding gas gaps

3) Number of fuel elements

4) Fuel element spacing

5) Coolant flow profile

6) Cladding thickness.

The operating conditions for the core ultimately determine the core lifetime, The design conditions for operation were originally set at $600 \mathrm{kwt}$ for 10,000 hours ${ }^{(1)}$ at a coolant outlet temperature of $1300^{\circ} \mathrm{F}$. The operating lifetime goal was subsequently increased to 12,000 hours. The effects of varying the coolant inlet and outlet temperatures, as well as the temperature rise across the core (flow rate), were investigated at power levels of 600 and $450 \mathrm{kwt}$. Mixed mean coolant outlet temperatures of 1200 and $1300^{\circ} \mathrm{F}$ were investigated.

The radial fuel-to-cladding gas gap was optimized to provide the maximum reactor lifetime at a given set of operating conditions. The radial gas gap is an extremely important design variable because of its effect on both the fuel phase change limit and the swelling limit (see Section IV). The axial fuel-tocladding gas gap must also be of sufficient size to allow ample room for axial fuel swelling and space for the released fission product gases to accumulate.

A third variable investigated was the number of fuel elements in the core. Under the constraints of Phase I of the study, core configurations with 211 elements and with 199 elements were considered. Phase I of the study specified the use of a rod-centered hexagonal fuel array. It also specified that the core vessel ID was to remain unchanged from the value previously specified for S8DS. The use of 199 elements was therefore necessitated if the thickness of the cladding material were increased while maintaining the previous cladding ID, if the

NAA -SR -12482

13

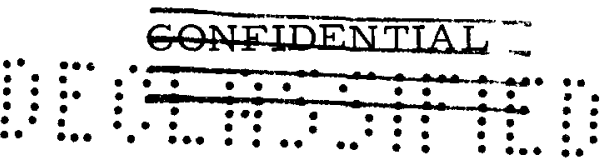


fuel element spacing (pitch) were increased while maintaining the previously specified element $O D$, or if the fuel-to-cladding gas gap were increased while maintaining the previously specified fuel rod OD and fuel element pitch.

Core configurations with 211 fuel elements and with 207 elements were considered in Phase II of the study. The 207 element configuration is a coolant channel centered triangular pitch array. (Consideration of fuel arrays other than hexagonal was allowed in Phase II of the study.) The use of this configuration may be desirable if it is deemed advantageous to change the coolant flow profile through the core by varying the element-to-element spacing. The obvious advantage of the 207 element core over the 199 element core is that the reactivity penalty is much less severe. However, the option exists to change the coolant flow profile by changing the coolant baffle plate while employing uniform element-to-element spacing.

Changing the cladding thickness has only a second order effect on the reactivity loss rate and phase change lifetime characteristics of the S8DR core. Since the reactivity limit on reactor lifetime is far removed from the fuel phase change and the swelling limits, the reactivity penalty associated with changing the cladding thickness is not unacceptable for S8DR. The potential incentive for changing the cladding thickness is derived from the resultant decrease in some of the cladding stresses. Such a change, however, must be critically scrutinized because it would be of possible significance in post-S8DR system designs.

Although the reactivity penalty associated with the use of thicker cladding is not unacceptable for $S 8 D R$, it would result in an increase in the shielded reactor envelope diameter for a flight reactor system. This increase in the shielded envelope diameter would cause an increase in the reactor shield weight and, therefore, an increase in the total system weight. Such a weight increase could be appreciable, especially for a $4 \pi$ shielded manned application. The use of the present cladding configuration would be quite desirable in the development of a minimum weight flight system.

NAA - SR - 12482

14

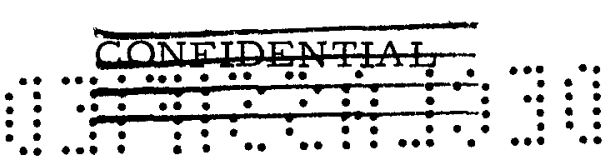




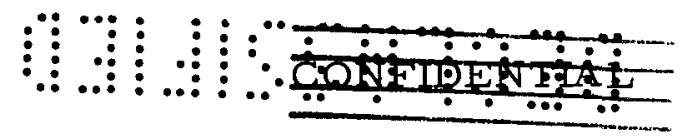

\section{DEPENDENT VARIABLES}

\section{A. LIFETIME LIMITATIONS}

The reactor operating lifetime will ultimately be limited by some condition which would either cause reactor shutdown or necessitate shutdown because of the occurrence of some undesirable condition. Examples of conditions which would force reactor shutdown are the depletion of the excess reactivity or a $\mathrm{NaK}$ coolant leak. Conditions which would dictate shutdown in order to maximize the technological gain of the S8DR test, would be the occurrence of $\beta$-phase fuel material or fuel swelling sufficient to close the fuel-to-cladding gas gap. Neither of the last two conditions would cause catastrophic reactor failure and shutdown, but shutdown would be necessary to prevent incipient fuel element failure. The lifetime limits assumed for this study are listed below.

1) Occurrence of $\beta$-phase fuel material

2) Closure of the fuel-to-cladding gas gap

3) Depletion of the available excess reactivity.

Other system failures were considered to be beyond the scope of this study.

The occurrence of $\beta$-phase fuel material is a result of the loss of the hydrogen moderator from the fuel material. The actual time at which phase change* occurs is determined by the amount of hydrogen which has been lost from the particular fuel element and by the temperature profil 2 of the fuel rod. The fuel swelling limit may be reached by closure of either the radial or axial fuel-tocladding gas gap. The axial gas gap in S8DR has been resized so that closure of the axial gap is an extremely remote possibility, although it appears to have been a limiting factor in the operation of S8ER. Both fuel swelling and fuel phase change are considered as lifetime limits because of their potential adverse effects on the integrity of the fuel element cladding. As evidenced by the postoperational examination and analysis of S8ER, cladding failure could soon occur, although the cladding integrity would not be breached at the moment when either of the two limits is reached.

*The occurrence of $\beta$-phase fuel material will be referred to as "phase change" throughout the remainder of this document, although the fuel passes through several other crystallographic phases.

$$
\text { NAA -SR }-12482
$$

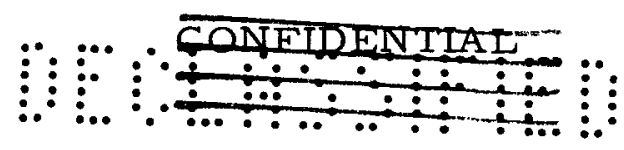




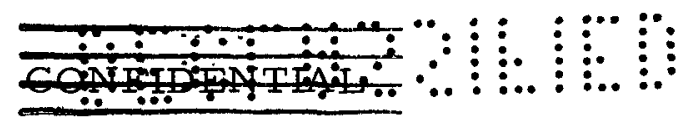

The reactivity limit has been defined as the point in time at which there is no longer sufficient controllable reactivity to continue full power operation at the rated outlet temperature. The reactivity limit has sometimes been further restricted by specifying that one control drum is stuck in the least reactive position ("one drum stuck" configuration) at the time the reactivity limit is reached, effectively reducing the controllable excess reactivity by the worth of a control drum. The excess reactivity of the reactor may be adjusted within limits by changing the thickness of the removable reflector shims. However, this could only be used to reduce the excess reactivity compared to the current fully shimmed reflector configuration.

\section{B. FUEL TEMPERATURES}

The fuel temperatures in the core are of primary importance in determining the hydrogen leakage from the fuel. Since the hydrogen leakage is exponentially dependent on the temperature (see Section IV-C), a small change in the temperature will make a large difference in the hydrogen leakage. The accuracy of the fuel temperature calculations thus becomes very critical in those cases where the reactor lifetime is limited by fuel phase change. It also appears that the fuel swelling may have temperature dependence, which is a second order effect over the range of temperatures of interest for S8DR (see Section IV-D).

The calculation of the fuel temperatures as a function of core position is a straightforward calculation which has previously been described. The calculation for the operating reactor is complicated, however, by the presence of fuel swelling and by the release of fission product gases to the fuel element gas gap. Fuel swelling reduces the fuel-to-clad gap, thus reducing the thermal resistance of the gas gap, and lowering the fuel temperature. On the other hand, the buildup of fission produce gases in the gap decreases the thermal conductivity of the gap and thus increases the fuel temperature. The two effects tend to offset each other, but the degree to which they do so depends on the size of the radial and axial gaps, the magnitude of the fuel swelling, and the magnitude of the fission gas release.

The fuel temperatures were calculated for each ring of fuel elements as a function of axial position along the element. Since the fuel elements are arranged on a hexagonal array, they are not actually positioned in rings. However, the

$$
\begin{gathered}
\text { NAA -SR }-12482 \\
\cdots 16
\end{gathered}
$$

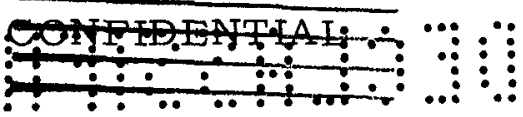




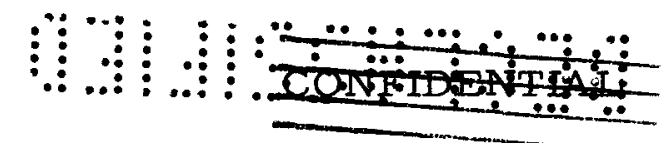

ring model can be used to describe the average element in each hexagonal ring. Both the TEMPR 8 and LOAFER ${ }^{(2)}$ computer codes use the ring model for their temperature calculations.

The temperatures in a given ring of fuel elements depend on both the power generated in that ring of elements and the amount of coolant flow around the ring. The detailed coolant flow description which is used in the TEMPR 8 calculation has been simplified for use in the LOAFER calculation used in this study to calculate the reactor lifetime. The agreement between the fuel temperatures as calculated using TEMPR 8 and with LOAFER has shown that the simplification in the model does not significantly impair the accuracy of the calculation. The radial and axial "flow factors" which are used to describe the coolant flow in TEMPR 8 were experimentally determined from hydraulic ex periments using a mock-up of the S8DS core vessel with the previously specified flow baffle plate.

The radial power profile for the S8DR core changes during operating lifetime, primarily because of the motion of the movable control drums. The power profile is considerably more peaked in the center of the core at the beginning-of-life than it is at the end-of-life. The radial power flattening during operation is due primarily to the inward rotation of the control drums to compensate for the reactivity losses caused by fuel burnup, fission product buildup, and hydrogen moderator loss. Power profiles representative of the beginningof-life, the end-of-life, and the lifetime averaged power profile were investigated to determine the sensitivity of the calculated time to phase change. The axial power profile is not appreciably effected by the rotation of the control drums.

Since the phase change calculation is quite sensitive to the temperatures which are used, the uncertainty associated with the temperature calculation is of considerable interest. The estimated uncertainty distributions in the calculated beginning-of-life and end-of-life peak fuel temperatures are shown in Tables 1 and 2 . It is noted that both the flow profile and the power profile are large contributors to the total uncertainty in the temperature calculation at both beginning-of-life and at end-of-life. It is noted, however, that fuel swelling and

NAA-SR - 12482

17

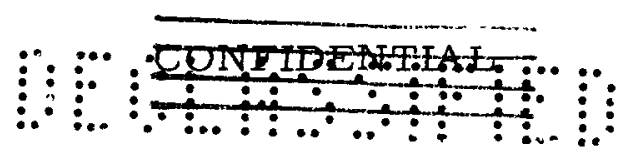


TABLE 1

DISTRIBUTION OF PEAK FUEL TEMPERATURE UNCERTAINTIES AT BEGINNING-OF-LIFE

\begin{tabular}{|c|c|c|}
\hline \multirow[b]{2}{*}{ Variable } & \multicolumn{2}{|c|}{ Uncertainty } \\
\hline & $(\% *)$ & $\left( \pm{ }^{\circ} \mathrm{F}\right)$ \\
\hline $\begin{array}{l}\text { Velocity Profile and Local } \\
\text { Perturbations }\end{array}$ & 8.3 & 28 \\
\hline Power Profile & 6.0 & 20 \\
\hline Gas Gap Thickness & 4.9 & 17 \\
\hline Fuel Conductivity & 4.0 & 14 \\
\hline Core Power & 3.5 & 12 \\
\hline Cladding OD & 3.0 & 10 \\
\hline Uranium, Hydrogen, Samarium & 2.4 & 8 \\
\hline Element Pitch & 2.3 & 8 \\
\hline Gap Conductivity & 2.0 & 7 \\
\hline Fuel Rod Diameter & 1.5 & 5 \\
\hline Ceramic Thickness & 1.2 & 4 \\
\hline Ceramic ID & & \\
\hline NaK Heat Transfer Coefficient & 0.6 & 2 \\
\hline Ceramic Conductivity & & \\
\hline Total Uncertainty (root mean sq) & $\sim 14$ & 48 \\
\hline
\end{tabular}

fission gas release effects become the largest source of uncertainty for the endof-life case. The total uncertainties quoted are the estimated tolerance (or $3-\sigma$ ) limits.

Although these uncertainty estimations were not directly used in the lifetime calculations, they are germane inasmuch as they indicate the items which are the largest contributors to the fuel temperature uncertainty. These items (flow profiles, power profile, gap thicknesses, fuel conductivity, and gap conductivity) are scrutinized in Section VI to determine their effects on the reactor lifetime calculations.

NAA-SR- 12482

18 
TABLE 2

DISTRIBUTION OF PEAK FUEL TEMPERATURE UNCERTAINTIES AT END-OF-LIFE

\begin{tabular}{l|r|r}
\hline \multicolumn{1}{c|}{ Variable } & \multicolumn{2}{c}{ Uncertainty } \\
\cline { 2 - 3 } & $(\%)$ & $\left( \pm^{\circ} \mathrm{F}\right)$ \\
\hline Gas Gap Conductance (gas gap thick- & 17.5 & 55 \\
nesses and thermal conductivity) & 8.3 & 26 \\
Velocity Profile and Local Perturbations & 6.0 & 19 \\
Power Profile & 4.0 & 12 \\
Fuel Conductivity & 3.5 & 11 \\
Core Power & 3.0 & 9 \\
Cladding OD & 2.4 & 7 \\
Uranium, Hydrogen, Samarium & 2.3 & 7 \\
Element Pitch & 1.4 & 4 \\
Other & $\sim 21$ & 65 \\
Total Uncertainty (root mean square) & & \\
\hline
\end{tabular}

\section{HYDROGEN LEAKAGE}

The integrated hydrogen leakage, together with the fuel temperature profile, determines the time of fuel phase change. The form of the equations used to calculate hydrogen leakage from the S8DR fuel elements has been discussed by Nathan. (3) The equation used in the LOAFER calculations for S8DR is shown in Equation 1.

$$
\varphi=A\left[K_{D} \sqrt{P} \exp \left(K_{1} / T\right)+K_{3} P \exp \left(K_{2} / T\right)\right]
$$

where

$$
\begin{aligned}
& \varphi=\text { hydrogen leakage }[\mathrm{cc}(\mathrm{STP}) / \mathrm{hr}] \\
& \mathrm{A}=\text { area of element at temperature } \mathrm{T} \\
& \mathrm{T}=\text { hydrogen barrier temperature } \\
& \mathrm{P}=\text { hydrogen pressure in the gas gap }
\end{aligned}
$$




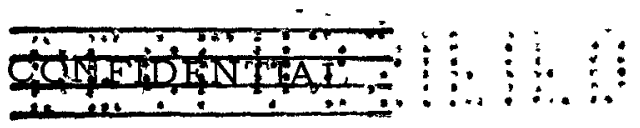

$$
\begin{aligned}
& \mathrm{K}_{\mathrm{D}}=\text { defect constant (also referred to as the "relative barrier } \\
& \quad \text { effectiveness) } \\
& \mathrm{K}_{1}, \mathrm{~K}_{2} \text {, and } \mathrm{K}_{3}=\text { constants }
\end{aligned}
$$

The constants in the equation given above are evaluated for the hydrogen leakage from a fuel element under isothermal conditions. Since a temperature gradient exists along the fuel rod during operation in the reactor, the equation must be evaluated at discrete points along the length of the rod and the leakage from each portion summed to obtain the total leakage from the element.

Calculations have indicated that the second term of Equation 1 will contribute only 5 to $10 \%$ of the total leakage during operation of S8DR. It is thus noted that the hydrogen leakage will proceed essentially as the square root of the gas gap pressure since the temperature profile along the length of the fuel rod remains fairly constant during the operating lifetime. However, the defect constant, $\mathrm{K}_{\mathrm{D}}$, is actually a parameter rather than a constant as was originally supposed. The value of the defect constant depends upon the fuel element history of thermal and mechanical inputs and has been shown experimentally to vary considerably during long-term testing.

The variation with time in the relative barrier effectiveness, $\mathrm{K}_{\mathrm{D}}$, is shown in Figure 1. It is noted that there is considerable variation in the value of $K_{D}$ with time at temperature. The magnitude of the relative barrier effectiveness for the 31 elements coated with AI-8763D indicates that they had a lower quality hydrogen barrier " than the seven elements that are currently undergoing testing, although the variation of $K_{D}$ with time for the 31 elements was not as severe as for the seven. The seven elements using the SCB-1 coating are more representative of the S8DR reference design and were produced using more advanced production processes than were the 31 elements. A direct comparison is therefore not valid, but certain trends in the data may be identified.

The data from the 31 elements, which were coated with the AI-8763D hydrogen barrier, is seen to be reasonably constant with a slight tendency to decrease in magnitude with operating time. It must be noted that the data for the 31 elements was for endurance testing only, contrasted to the data for the *Higher values of $\mathrm{K}_{\mathrm{D}}$ indicate relatively lower hydrogen barrier quality. A "perfect" hydrogen barrier would have $\mathrm{K}_{\mathrm{D}}=0$.

NAA-SR - 12482

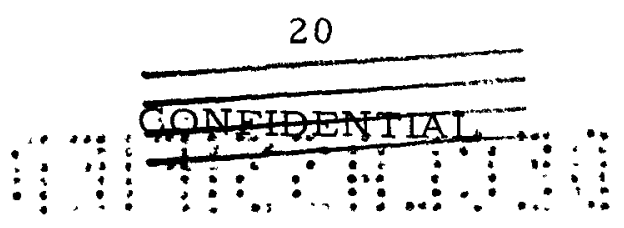



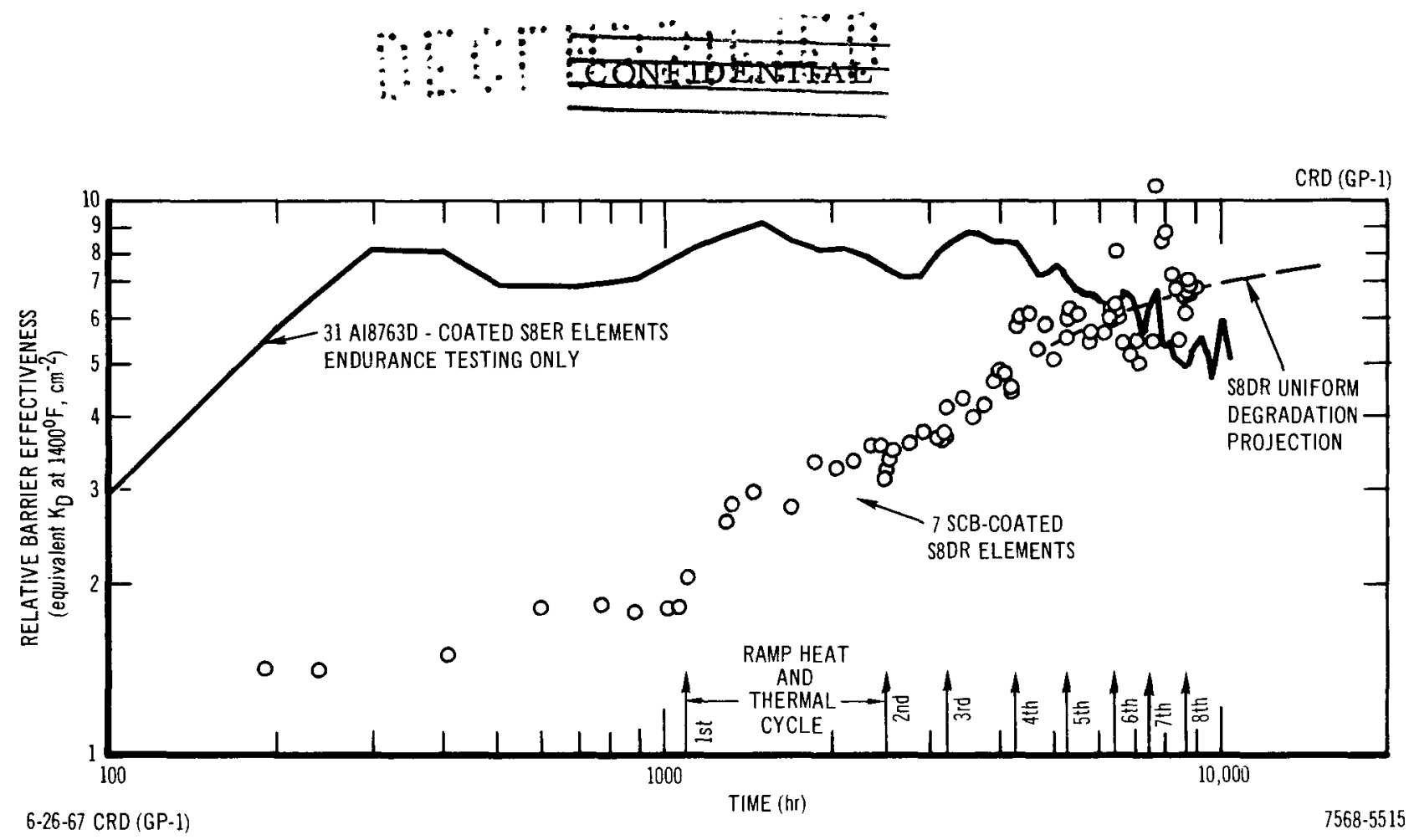

Figure 1. Time Dependence of Relative Barrier Effectiveness

seven elements coated with $\mathrm{SCB}-1$ which were subjected to a series of ramp heat and thermal cycle tests approximately every 1000 hours. The data from the 7 -element test indicate that the elements are sensitive to the thermal inputs, although previous results indicate that the SCB-l-coated elements are not as sensitive to thermal inputs as are the AI-8763D-coated elements. The thermally cycled elements were considered more representative of the actual operating conditions than elements which were tested at uniform temperature without thermal cycling during extended operation.

The ramp heat and thermal cycle inputs to which the seven elements were subjected are described in Figure 2. The elements were subjected to the inputs at intervals of approximately 1000 hours during the long-term endurance testing. To date, they have received the inputs a total of seven times. The test is continuing. While it is predicted that these inputs were more severe than the elements will probably encounter during the actual operation of S8DR, it was believed necessary to account in some manner for the sensitivity of the elements to thermal inputs which would be encountered during operation. Since no analytical prediction of the sensitivity is currently available, the data from the 


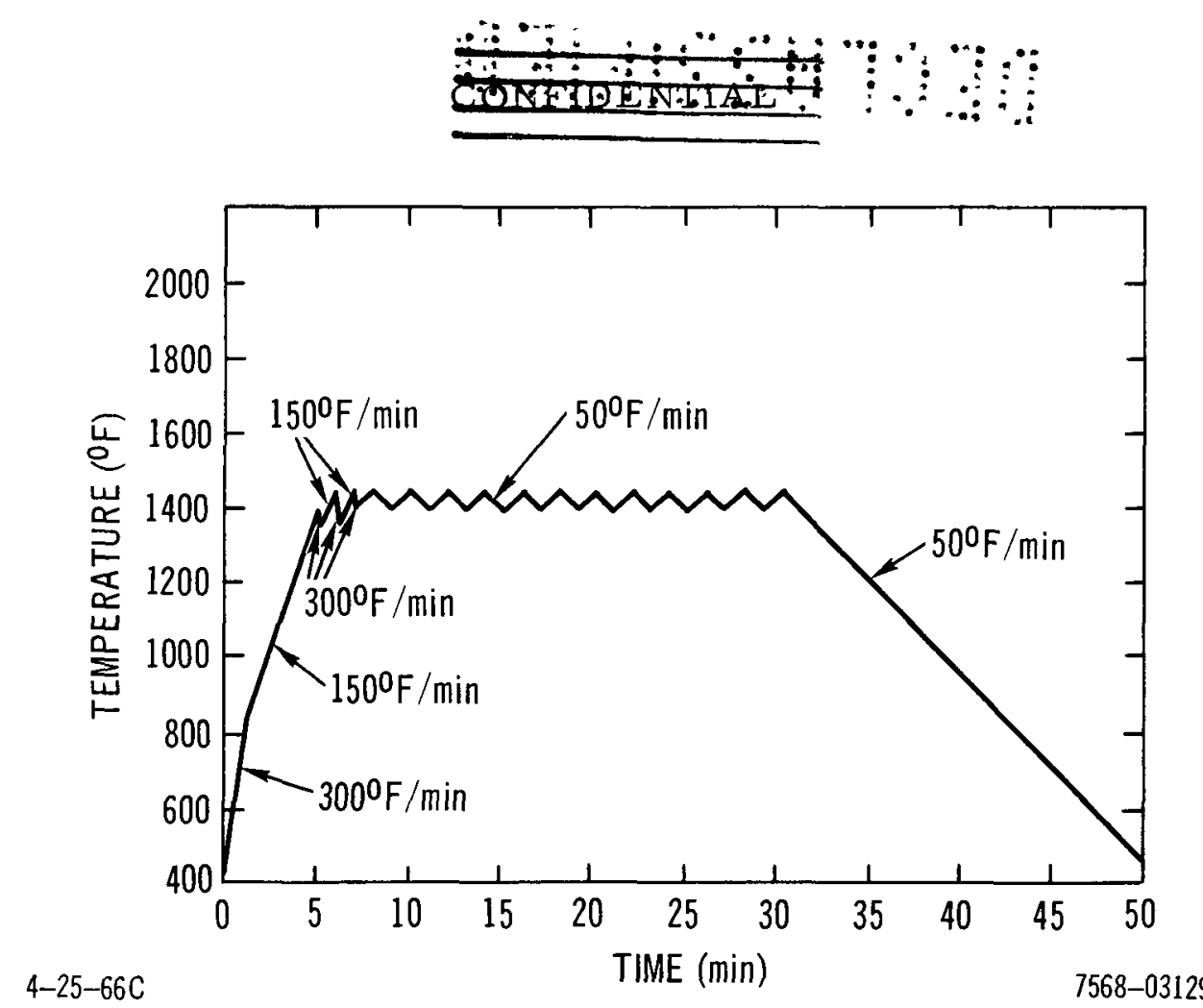

Figure 2. Temperature Cycles for S8DR Developmental Elements

7-element test was used as most applicable. Prediction of S8DR hydrogen leakage based on the data from the 7 -element test therefore have the implicit assumption that the fuel elements in S8DR will undergo, at corresponding times, the same kind and amount of thermal inputs that the seven elements experienced, and will respond in a similar manner to these inputs.

Significant improvements in the barrier adherence and in the process controls associated with the production of the barriers have been achieved since the seven elements were produced. However, long-term endurance testing and thermal cycle test data are not available for the improved barriers. Since it is not possible to accurately assess in a qualitative fashion the improvement in the barrier performance, the 7-element data were used. They more closely approximated the S8DR conditions and fuel elements than any elements which had undergone long-term testing.

As noted, the values of the relative barrier effectiveness are inferred from hydrogen leakage measurements during isothermal testing. The values of $\mathrm{K}_{\mathrm{D}}$ thus inferred are based on the assumption that the hydrogen leakage is uniform along the length of the fuel element. Data which have recently become available

NAA -SR -12482

22 


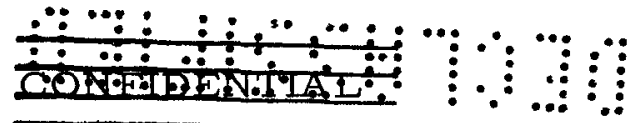

In spite of the difficulties associated with the use of the 7-element data on the variation of the relative barrier effectiveness, the data have been used to predict the hydrogen leakage for S8DR. It is believed that the data used will result in conservative estimates (shorter than will actually occur) of the time required to reach fuel phase change. Sufficient endurance data for hydrogen leakage from S8DR fuel elements under conditions approximating the operating conditions of the reactor are not currently available to make a more accurate estimate. The small amount of permeation scan data which is available has been used to estimate the effect of "cold end" leakage. The effect of the difference in the thermal inputs experienced by the seven elements, as compared to the fuel elements in the operating S8DR reactor, has not been evaluated, due to a lack of pertinent data.

\section{FUEL SWELLING}

The fuel swelling correlations which were used in this study, and the data from which they were derived, are discussed in detail by Birney. (4) The fuel swelling data and the correlations which were used are shown in Figure 3 . It is

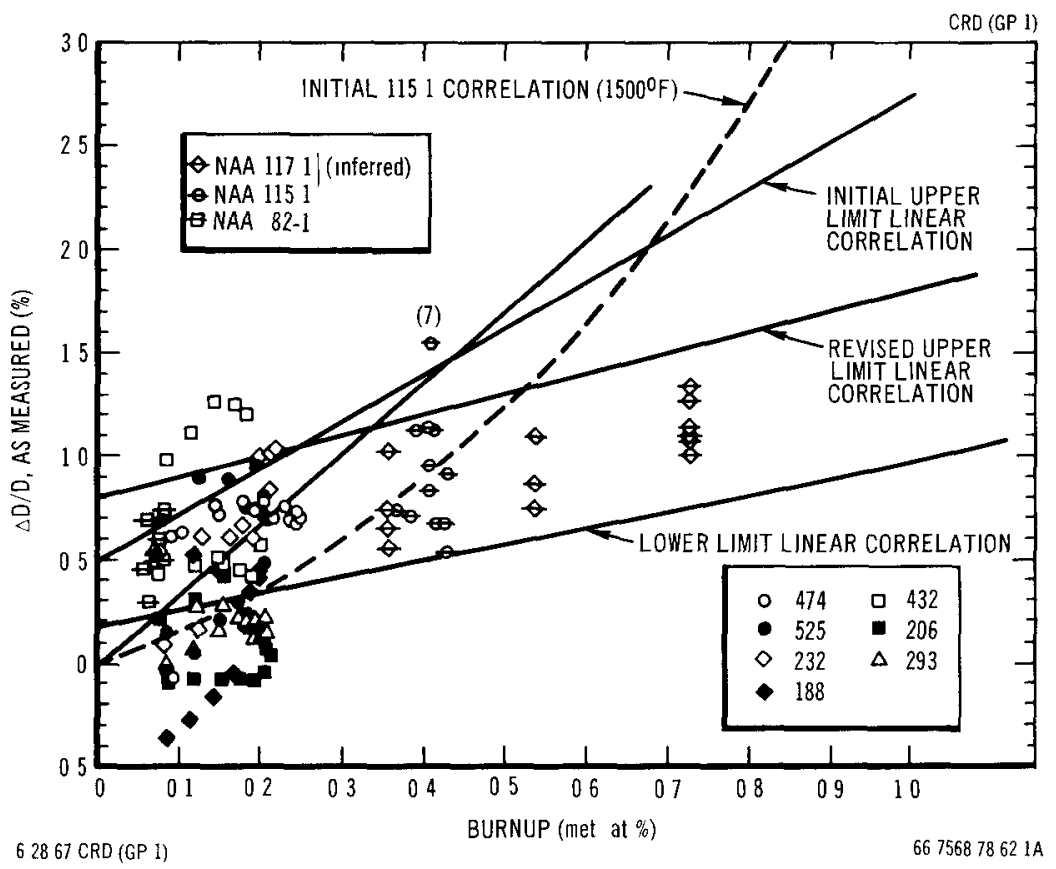

Figure 3. Diametral Growth vs Burnup for Intact S8ER Elements

NAA - SR - 12482

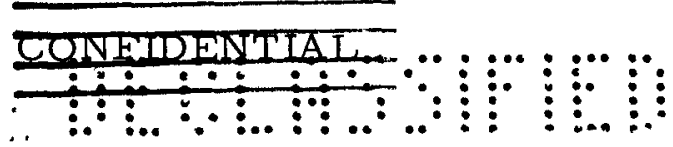




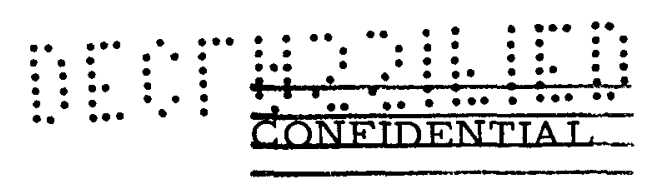

noted that the two upper limit linear correlation lines, as well as the lower limit linear correlation line, do not have zero intercepts. It is also noted that a small amount of data falls outside the limit bands.

The data which lie below the limit bands represent fuel which suffered relatively large hydrogen loss with a consequent increase in density and decrease in diameter. The data which fall above the revised upper limit line represent fuel which underwent severe axial restraint and, as a consequence, suffered greater than normal diametral growth. Since axial restraint will not be present in S8DR; the fact that the data lay above the "upper limit" swelling correlation was not of grave concern. The average expected diametral fuel growth will be considerably less than that indicated by the upper limit correlations.

The fact that none of the linear swelling correlations has a zero intercept at zero burnup is indicative that fuel swelling is a function of some phenomenon in addition to fuel burnup. Examination of the available fuel swelling data for SNAP type fuel material indicated that the fuel swelling did not exhibit a strong coupled burnup-temperature dependence over the range of temperatures generally of interest in SNAP applications (1200 to $\left.1500^{\circ} \mathrm{F}\right)$. However, the data did indicate that fuel swelling was primarily dependent upon the movement of certain hydrogen concentration during operation at temperature. The movements of these local concentrations, or "boundaries," were caused by the changing hydrogen concentration in the fuel and, to a lesser extent, by temperature changes in the fuel.

The magnitude of fuel swelling has a direct effect on the fuel temperatures as noted in Section IV-B. The time dependence of the fuel swelling offset thus will influence the fuel rod temperature profile as a function of time. The time dependence of the swelling offset is currently not known. Thus, the effect of the offset swelling on the fuel phase change lifetime may not be accurately calculated. It is possible, however, to establish the limits of the offset swelling effect.

As noted in Section I, the fuel growth which was observed during the postoperation examination of S8ER fuel was much larger than expected. Prior to the post-operation examination of S8ER it had been believed that the fuel growth would be strongly temperature dependent. Further, the relatively large fuel growth

NAA -SR -12482 


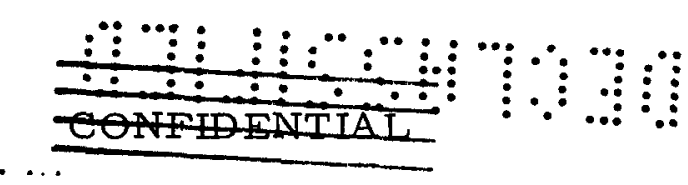

at very low burnup was not suspected. The limited data which were available at the time S8ER was designed had been analyzed and fitted with an equation which yielded the expected strong temperature dependence. The Miller swelling correlation $^{(5)}$ was the culmination of that effort.

Comparison of the fuel growth predicted using the Miller correlation, and growth predicted using the linear correlation limit lines of Figure 3, is shown in Figure 4. It is noted that the disagreement is most severe at low fuel burnups (up to about 0.5 metal at. \%). The maximum fuel burnup for S8DR will be 0.3 metal at. \%. Since the Miller correlation was used to size the S8DR fuel-tocladding gas gaps, and was instrumental in decision to employ strongly peaked coolant flow profiles in both S8ER and S8DR, the severity of the disagreement becomes immediately obvious.

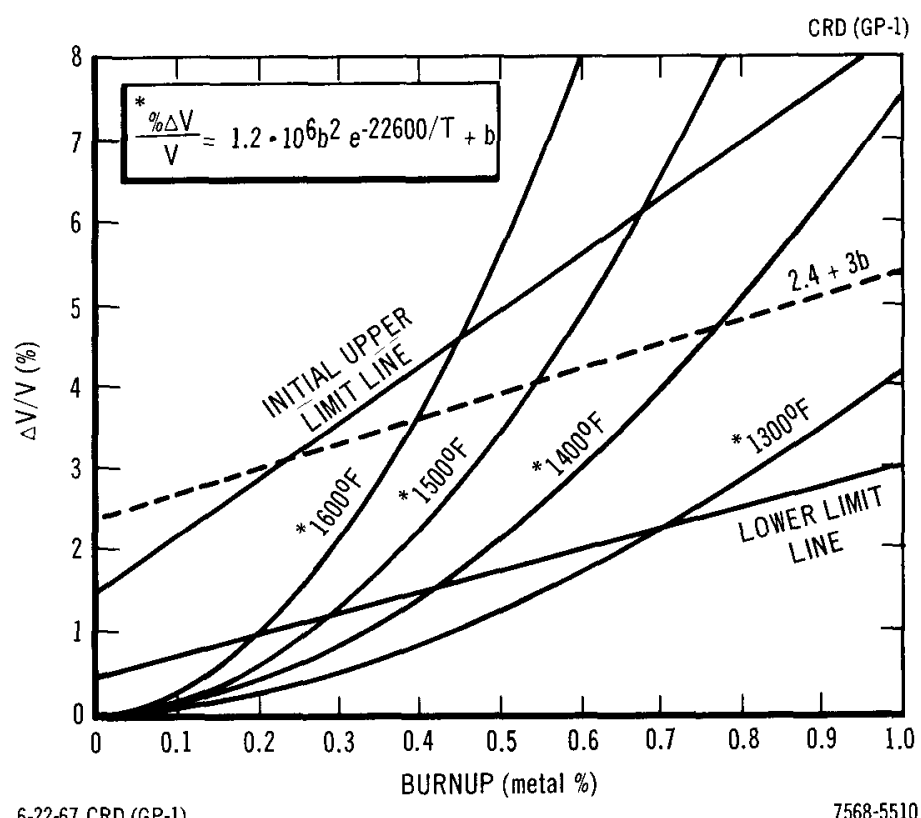

Figure 4. Predicted Fuel Growth vs Burnup 


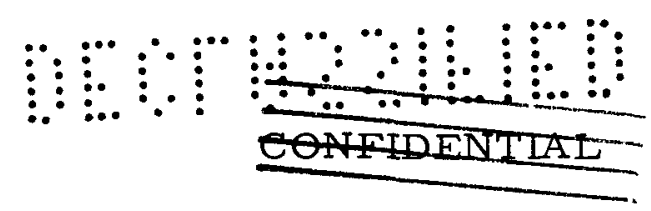

\section{CALCULATIONAL METHODS}

\section{A. LIFETIME CALCULATIONS}

The LOAFER computer code was used to calculate the phase change lifetimes and the reactivity limits for each given configuration. The code performs a step-wise integration of the hydrogen loss as a function of time. The effect on fuel temperature of fuel swelling, and of fission gas release to the fuel-tocladding gas gap, is considered for each fuel ring for each time step. The fuel swelling limits may be directly determined using the LOAFER calculation if it is assumed that the fuel swelling is a linear function of fuel burnup with no offset. A hand calculation may then be used to correct the fuel swelling limit to account for offset swelling. The hot operating reactivity losses are also calculated using LOAFER. These losses include the losses from fission product buildup (other than xenon-135 and samarium-149, which are treated separately), fuel depletion, and hydrogen loss. The reactivity gain which results from prepoison (Sm-149) burnout is also calculated as a function of operating time. Using the total cold excess reactivity of the system (which is independently calculated with a neutron transport theory code and normalized to previous reactivity measurements), the excess reactivity remaining as a function of time may be calculated by subtracting the short term reactivity losses and the LOAFER calculated values of the hot operating losses. The short term losses include xenon-135 buildup, hydrogen redistribution, and the temperature and power defects. The primary cause of reactivity loss during operation is the loss of the hydrogen from the fuel material. The reactivity limit may then be specified when the reactivity contingency is specified.

\section{B. TEMPERATURE CALCULATIONS}

The fuel, cladding, and coolant temperature calculations have been performed with varying degrees of sophistication. The TEMPR 8 computer code was used for most of the survey calculations to investigate fuel and cladding temperatures. As previously noted, TEMPR 8 employs a ring model for the temperature calculations. The LOAFER temperature calculations are based on a calculational model which is nearly identical to that used in TEMPR $u$

NAA -SR - 12482

27 


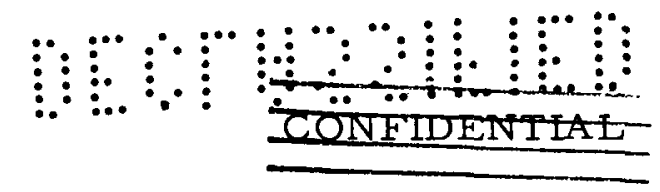

operation before reactor shutdown could be achieved after reaching the phase change limit than could be attained after the fuel swelling limit had been reached. The ultimate mechanism which makes the appearance of beta phase fuel undesirable is the increase in the fuel growth rate. Thus, after the onset of fuel phase change, the fuel must swell an additional amount to cause cladding failure. The resultant cladding failure would cause an increase in the hydrogen loss rate (reactivity loss), which ultimately would cause the reactivity limit to be reached.

Separate sets of calculations were performed to determine the effect of the swelling correlation on the gas gap optimization. The gap optimization was first performed using linear fuel swelling correlations. The "initial upper limit linear" fuel swelling correlation was used to calculate the fuel swelling limits, while another linear swelling correlation was used to determine fuel temperatures which were utilized in the hydrogen loss calculations. As may be noted from Figure 3, both correlations were linear with fuel burnup, but the "initial linear" correlation included an "offset." Neither correlation included any temperature dependence, however, and the time dependence of the swelling offs et remains unknown.

Since, as discussed in Section IV-B, the magnitude of the fuel swelling influences the fuel temperatures, it was necessary to assume a time-dependent behavior for the fuel swelling. It was assumed that the diametral fuel growth could be approximated by,

$$
\% \Delta \mathrm{D} / \mathrm{D}=3.33 \mathrm{~b}(\text { metal at. } \%)
$$

The fuel growth for the S8DR peak fuel burnup as calculated from Equation 2 is very nearly equal to the growth calculated using the initial linear correlation at that burnup. The fuel swelling as calculated from Equation 2 was used to calculate the fuel temperatures for the hydrogen loss and fuel phase change calculations while the offset initial linear correlation was used to calculate the magnitude of the fuel growth.

A second fuel swelling rate was assumed during Phase I of the study. That fuel growth correlation was based on the results of the NAA-115-1 fuel ir radiation 


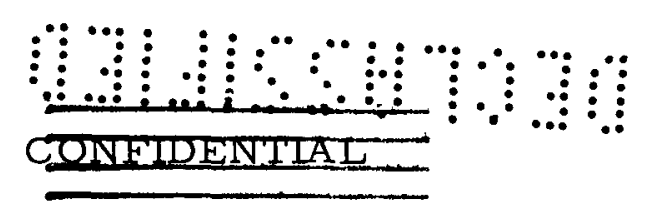

data and contained a term which was exponentially dependent on the fuel temperature. The lifetime calculations during the second part of the Phase I studies utilized the "initial NAA-115-1 fuel growth correlation" both to calculate the expected fuel growth and as a basis for the fuel temperature calculations. As may be seen in Figure 3, it predicted considerably less growth with $1500^{\circ} \mathrm{F}$ fuel temperature and 0.3 metal at. \% burnup than did the linear fuel swelling correlation. It appears, from an examination of the pertinent S8ER fuel growth data, that the initial NAA-115-1 fuel growth correlation will not accurately predict the peak fuel growth for S8DR.

The results of the diametral gas gap optimization as a function of the two fuel swelling assumptions are shown in Figure 5. It is noted that the optimum diametral gap for the cases with the NAA-115-1 swelling correlation is nearly a factor of two less than for the initial upper limit linear correlation. However, it is also noted that the phase change lifetime calculated using the NAA-1 15-1 correlation is greater than that calculated using the upper limit linear correlation, for a given gap size. Thus, the gap may be optimized based on the initial upper limit linear correlation and provide operation of at least as long as that predicted by the optimization point.

The effect on the gap optimization of changing the core power level may be seen by comparing Figure 5 with Figure 6. It is noted that the gap optimization remained essentially constant for constant coolant outlet temperature, even though the operating lifetime was increased.

\section{Coolant Flow Profile}

It has been recognized for some time that the combination of greater-thanexpected hydrogen loss and greater-than-expected fuel growth had the combined effect of making the previously specified S8DR flow profile non-optimum. Calculations had shown that a change in the coolant flow profile could add to the S8DR operating lifetime before the occurrence of the phase change lifetime limits. Three alternatives were present with regard to the coolant flow profile:

1) Change the flow profile by redesigning the coolant baffle plate,

2) Change the flow profile by using variable element-to-element spacing, or

3) Use the previously specified flow profile.

$$
\text { NAA -SR }-12482
$$



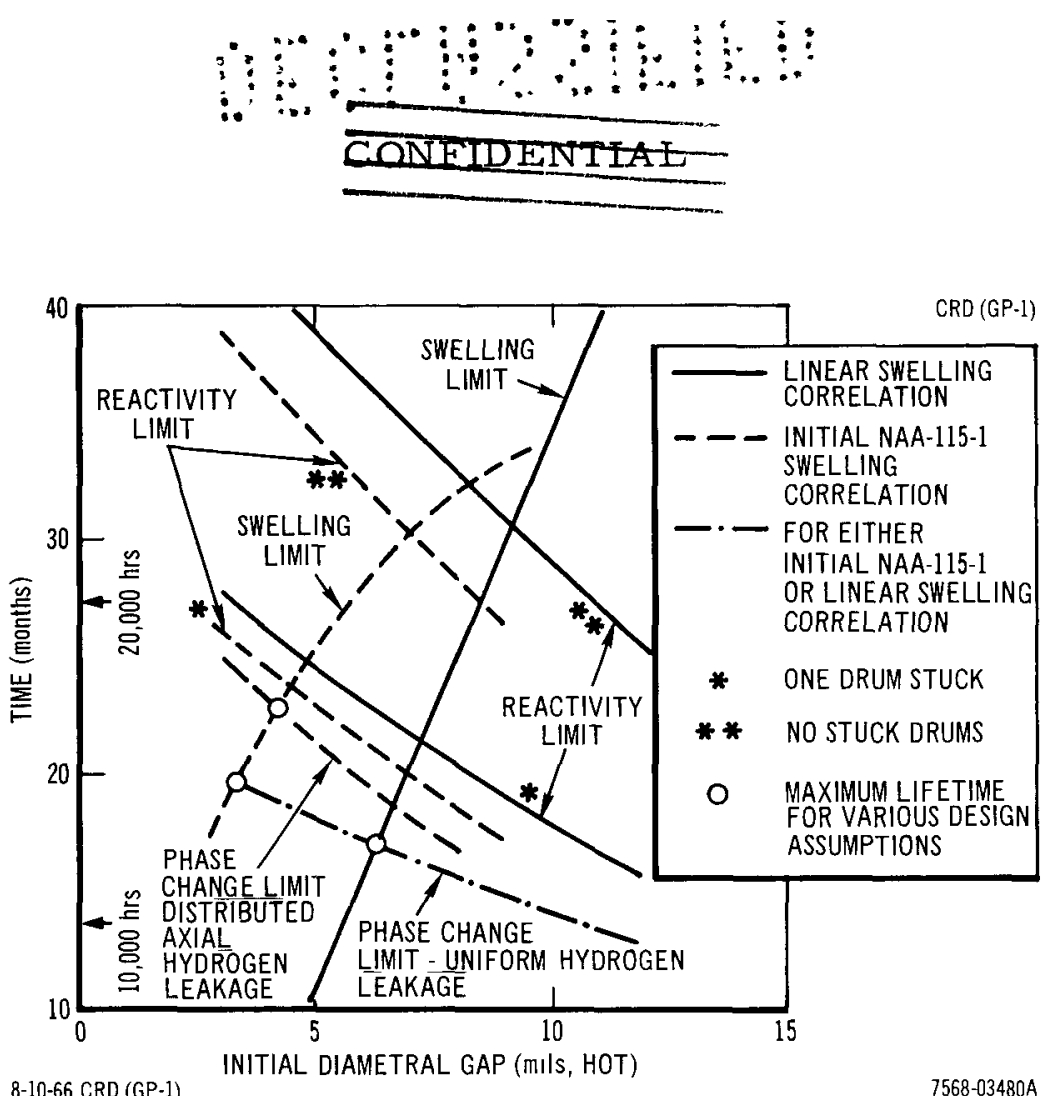

Figure 5. S8DR Lifetime vs Initial Gap (600 kwt, 211 -Element Core, $1300^{\circ} \mathrm{F}$ Outlet, Present Flow Profile)

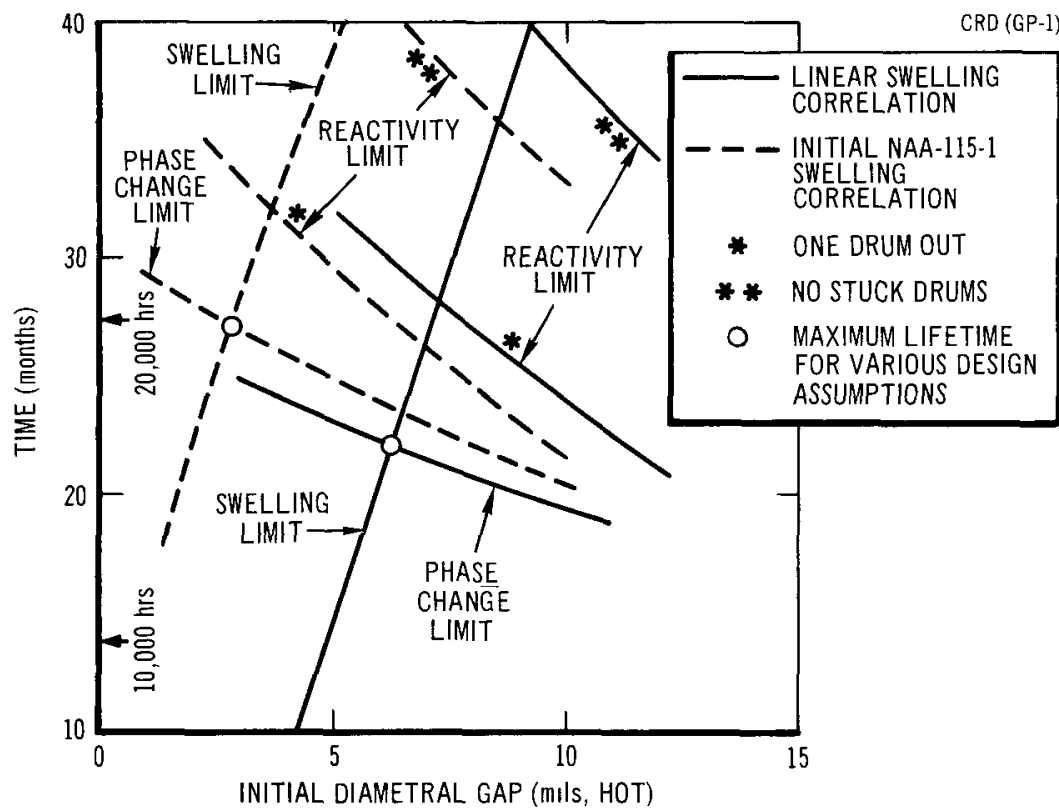

8-10-66 CRD (GP-1)

7568-03481A

Figure 6. S8DR Lifetime vs Initial

Gap (450 kwt, 211 -Element Core, $1300^{\circ} \mathrm{F}$ Outlet, Present Flow Profile)

NAA -SR - 12482 


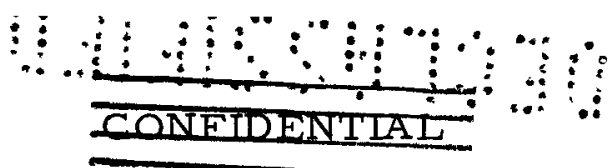

The question was whether the increased operating margin would justify the additional expense and time which would be required. The respecified flow profile would require hydraulic tests to verify the design and the manufacture of some new components (such as the baffle plate, and possibly the grid plates). It appeared that the previously specified flow profile would provide slightly in excess of $12,000 \mathrm{hr}$ of S8DR operation before the occurrence of one of the limits. The calculated increase in operating capability is shown in Figure 7.

Either of the first two alternatives could be used to produce the more desirable flow profile. The first alternative would necessitate the performance of hydraulic tests for several alternate baffle plate designs. Final selection would be based on the empirical evaluation of the baffle plate designs examined in the hydraulic tests.

The second alternative appeared more attractive than the first from an analytical point of view, except that it necessitated the use of no more than 199 fuel elements (under the constraints of Phase I of the study). Its chief advantage over the first alternative was that the coolant flow through the core could be

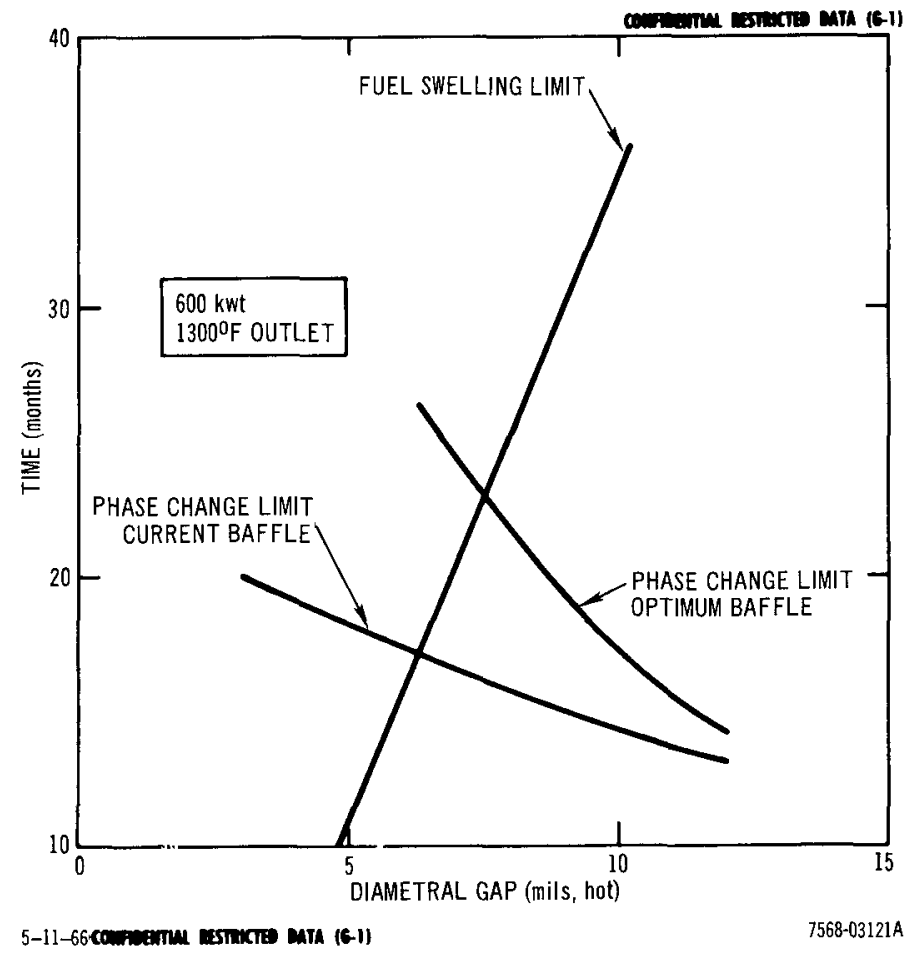

Figure 7. S8DR Lifetime Studies Flow Profile Variation

NAA-SR -12482

34 


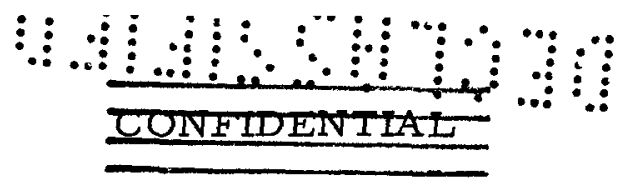

TABLE 4

TIME TO PHASE CHANGE WITH CURRENT S8DR FLOW PROFILE*

\begin{tabular}{c|c|c|c}
\hline $\begin{array}{c}\text { Power } \\
\text { (kwt) }\end{array}$ & $\begin{array}{c}\text { Inlet } \\
\text { Temperature } \\
\left({ }^{\circ} \mathrm{F}\right)\end{array}$ & $\begin{array}{c}\text { Swelling } \\
\text { Correlation }\end{array}$ & $\begin{array}{c}\text { Time to } \\
\text { Phase Change } \\
\text { (months) }\end{array}$ \\
\hline 600 & 1100 & Maximum Linear & 17 \\
660 & 1100 & Maximum Linear & 15 \\
540 & 1100 & Maximum Linear & 20 \\
600 & 1000 & Maximum Linear & 52 \\
600 & 1200 & Maximum Linear & 8 \\
450 & 1100 & Maximum Linear & 23 \\
450 & 1200 & Maximum Linear & 11 \\
600 & 1100 & $1 / 2 \times$ Maximum Linear & 16 \\
600 & 1100 & $1 / 3 \times$ Maximum Linear & 16 \\
\hline
\end{tabular}

$*$ Assumptions: Fuel conductivity $=7.5 \mathrm{Btu} / \mathrm{hr}-\mathrm{ft}-{ }^{\circ} \mathrm{F} ; 211$ fuel elements; uniform axial hydrogen leakage coefficient

TABLE 5

TIME TO PHASE CHANGE IN S8DR WITH VARIABLE AXIAL HYDROGEN LEAKAGE COEFFICIENT

\begin{tabular}{c|c|c|c}
\hline $\begin{array}{c}\text { Power } \\
\text { (kwt) }\end{array}$ & Flow Profile & $\begin{array}{c}\text { Axial Hydrogen } \\
\text { Leakage }\end{array}$ & $\begin{array}{c}\text { Time to } \\
\text { Phase Change } \\
\text { (months) }\end{array}$ \\
\hline 600 & S8DR & $*$ & 17 \\
600 & S8DR & $\dagger$ & 20 \\
600 & Optimum & $*$ & 21 \\
600 & Optimum & $\dagger$ & 25 \\
\hline
\end{tabular}

*Uniform axial hydrogen leakage coefficient

†Hydrogen leakage fractions vary from 0.40 (cold end), 0.20 (tube), and 0.40 (hot end) at beginning-of-life to $0.80,0.05$, and 0.15 at

24 months operation

As sumptions: $1100^{\circ} \mathrm{F}$ inlet temperature; 211 fuel elements; fuel conductivity $=7.5 \mathrm{Btu} / \mathrm{hr}-\mathrm{ft}-{ }^{\circ} \mathrm{F} ;$ maximum linear swelling correlation.

NAA -SR - 12482 


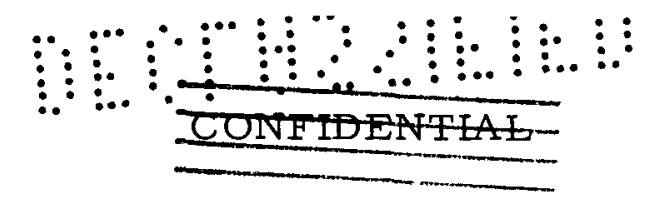

TABLE 8

TIME TO PHASE CHANGE AS A FUNC TION OF CORE TEMPERATURE RISE $(600 \mathrm{kwt})$

\begin{tabular}{|c|c|c|}
\hline \multirow[b]{2}{*}{$\Delta \mathrm{T}^{*}\left({ }^{\circ} \mathrm{F}\right)$} & \multicolumn{2}{|c|}{ Time to Phase Change (months) } \\
\hline & $\begin{array}{c}\text { S8DR } \\
\text { Flow Profile }\end{array}$ & $\begin{array}{l}\text { Optimized } \\
\text { Flow Profile }\end{array}$ \\
\hline 150 & 18 & 20 \\
\hline $\begin{array}{c}200 \text { (design } \\
\text { valve) }\end{array}$ & 17 & 21 \\
\hline 300 & 14 & 18 \\
\hline
\end{tabular}

*Outlet temperature constant at $1300^{\circ} \mathrm{F}$

The initial upper limit linear, temperature independent, swelling correlation was used for this phase of the study. As a result, the fuel growth was a constant for a given power and operating time (fuel burnup). It is seen from Table 4 that decreasing the fuel swelling by factors of two and three had only very small effects on the calculated phase change lifetime.

It is noted from Tables 5 and 6 that the hydrogen leakage assumptions can give rise to rather large variations in the calculated phase change lifetime. As was pointed out in Section IV-C, there is considerable uncertainty associated both with the isothermal hydrogen leakage as a functi on of operating time and thermal inputs, and with the distribution of the isothermal leakage along the length of the elements. The data in Table 5 give an indication of the effect of assuming that the isothermal hydrogen leakage is predominantly from the ends of the fuel element. The data in Table 6 give an indication of the effect of an estimated $1-\sigma$ uncertainty on the extrapolated hydrogen leakage coefficient, $K_{D}$.

The effect of initial hydrogen concentration in the fuel on the phase change lifetime is illustrated in Figure 8 . The variation in the $\mathrm{N}_{\mathrm{H}}$ of the fuel rods which have been manufactured for use in S8DR is from 6.00 to 6.15. The average $\mathrm{N}_{\mathrm{H}}$ of the as-built rods is 6.07. The distribution of the $\mathrm{N}_{\mathrm{H}}$ in the 278 as-built rods is shown in Figure 9. The three rods with $\mathrm{N}_{\mathrm{H}}$ of less than 6.0 will not be used in S8DR.

NAA -SR -12482 


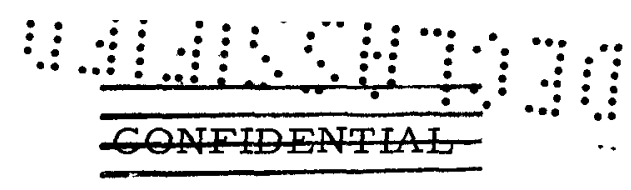

The effect of variation in the assumed thermal constants is shown in Table 7. The effective film heat transfer coefficient which has been used for the majority of the calculations, $1850 \mathrm{Btu} / \mathrm{hr}-\mathrm{ft}^{2}-{ }^{\circ} \mathrm{F}$, is conservative inasmuch as it applies for an element which is in contact with the adjacent six fuel elements. The value of $2500 \mathrm{Btu} / \mathrm{hr}-\mathrm{ft}^{2}-{ }^{\circ} \mathrm{F}$ would be a more representative value for a fuel element with 10-mil spacing between it and all adjacent elements. In effect, the lower value which has been employed may be considered as a pseudo hot-channel factor. It is further reiterated that the fuel thermal conductivity value of $7.5 \mathrm{Btu} / \mathrm{hr}-\mathrm{ft}-{ }^{\circ} \mathrm{F}$ which was used in this phase of the study appears to be very conservative. Even with these severe assumptions, the nominal calculated lifetime of 17 months exceeds the design requirements of 12,000 hours of operation (16.4 months) at rated power and temperature.

The data shown in Table 8 indicate the effect of changing the core $\Delta T$. It is noted that the phase change lifetime decreases with increasing $\Delta \mathrm{T}$ for the previously specified S8DR flow profile, although the reactivity loss decreases. When the flow is optimized, the maximum phase change lifetime occurs at the design core $\Delta \mathrm{T}$ of $200^{\circ} \mathrm{F}$.

Finally, it is important to realize that the fuel phase change limit is considered to have been reached whenever any fuel element in the core forms beta phase fuel material at any location within the element. Due to the high coolant flow rate (peaking of the flow profile) in the center of the core with the previously specified S8DR flow profile, the fuel temperatures in the center of the core are lower than in the outer fuel rings. (These effects are discussed in detail in Section VI-D.) Consequently, fuel phase change first occurs in Ring VIII of the core when the previously specified S8DR flow profile is employed. This may not at first seem to be of consequence, until it is remembered that Ring VIII contains 42 fuel elements. It would therefore seem desirable to have fuel phase change occur in a ring with fewer elements. Ideally, fuel phase change would occur simultaneously in all fuel elements in the core, if the coolant flow were optimized and the phase change lifetime maximized. However, other factors must also be given proper consideration.

NAA -SR - 12482

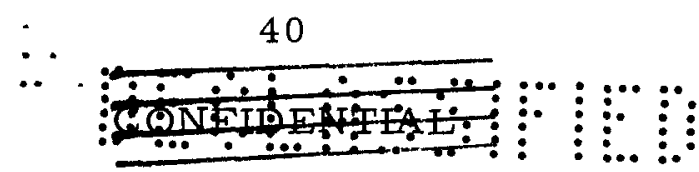




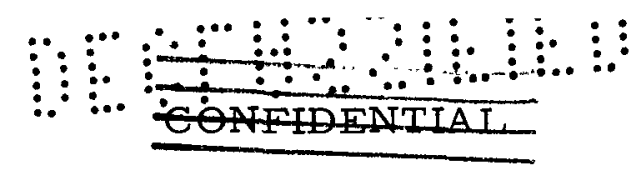

\section{REAC TIVITY LIMITS}

The S8DR reactor has been designed to reach the fuel phase change and fuel swelling limits before it reaches the reactivity limit. The reactivity limit has been defined as that point beyond which there is not sufficient controllable excess reactivity to maintain operation at rated conditions with some specified reactivity contingency. The amount of contingency has varied from zero to about $\$ 4.00$ (corresponding to one control drum stuck in its least reactive position). The current approach has been to denote the lifetime both with zero contingency, and with one drum stuck. The reactivity limit is then shown as a band rather than as a single line.

Only in those cases where the number of fuel elements is reduced to 199 , or where the cladding thickness is increased to $15 \mathrm{mils}$ while reducing the fuel rod diameter by a corresponding amount, does the reactivity limit become close to the phase change and fuel swelling limits. In general, there is a reactivity margin (no drums stuck) of approximately $\$ 5.00$ to $\$ 6.00$ after 12,000 hours operation at $600 \mathrm{kwt}$ and $1300^{\circ} \mathrm{F}$ coolant outlet temperature.

\section{THERMAL PERFORMANCE}

In general, the considerations of S8DR thermal performance fell into the two general categories: (1) Calculations for average elements in a given ring and, (2) individual element calculations including coolant flow in individual coolant channels and asymmetry effects.

The results of typical ring calculations are shown in Figure 10. The variation in peak centerline fuel element temperature as a function of core position is shown for two flow profiles and for 199-and 211 -element cores at beginningof-life and at end-of-life. The peaking of fuel temperature in Ring VIII at endof-life for the previously specified S8DR flow profile is noted. The shift in the fuel temperature with lifetime is caused by fuel swelling and by rotation of the control drums. Ring temperature calculations such as this are utilized in the LOAFER calculations of fuel phase change and reactivity loss.

The results of an individual element calculation for an optimized flow profile are shown in Figure 11. The temperatures are discontinuous since the flow from channel to channel may be discontinuous because of the area differences,

$$
\text { NAA -SR - } 12482
$$



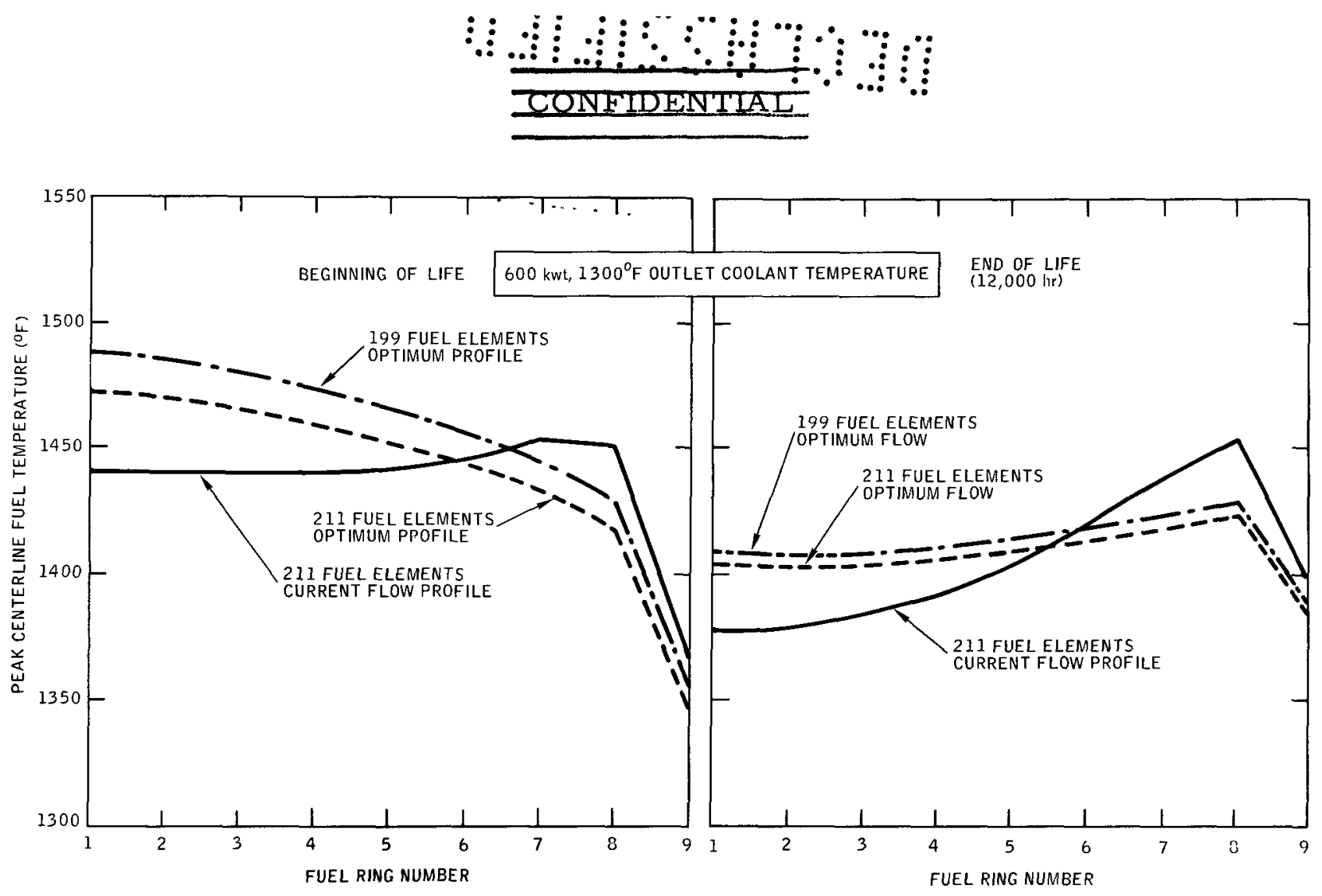

$12-5-66$ UNC

Figure 10. Typical "Ring" Temperature Calculations

and because of the absence of coolant crossflow for this variably spaced, optimized flow profile core. The actual channel flow profile calculated for this core is shown in Figure 12. The smoothed optimized flow profile used for the ring model calculations is also shown. The agreement between them is very good.

The individual element analysis was also used in considerable detail to evaluate the asymmetry and spacing effects on the fuel and cladding temperature. Although the temperatures calculated with the ring model are quite adequate for calculations of hydrogen loss, the detailed element calculations such as described here are necessary to evaluate the thermal stresses in the cladding, barrier, and fuel. (Section VI-E discusses the stress calculations in more detail.) The circumferential variation in the cladding, barrier, and fuel temperature for an S8DR type fuel element is shown in Figure 13.

The thermal effects of varying the element-to-element spacing and changing the cladding thickness are shown in Figures 14 and 15 . Increased element-toelement spacing offers a reduction in the circumferential temperature "ripple"

$$
\text { NAA-SR - } 12482
$$


in the cladding and it also reduces the possibility that adjacent elements will touch each other during operation. Since the gas gap in the element acts as a thermal insulator, it effectively isolates the fuel surface from the cladding for rods which are symmetrical within the cladding tube, and the cladding temperature is therefore required to follow the NaK temperature. The reduction in the average cladding temperature with an increase in the element-to-element spacing is about half the amount of the peak cladding temperature reduction.

The thermal effects of increasing the cladding thickness are relatively small, as may be seen in Figure 15. The reduction in the circumferential temperature ripple is due to the improved circumferential conduction in the cladding. The corresponding reduction in the peak fuel temperature is minimal.

The circumferential temperature ripple for the case in which the fuel rod contacts the cladding tube is shown in Figure 16. It is noted that the temperature difference between the cladding and the fuel is more pronounced than for the case with the symmetrical fuel rod shown in Figure 13.

CENTERLINE ELEMENT $Z / L=0.5$

$$
\overline{\mathrm{T}}_{\mathrm{NaK}}=1171^{\circ} \mathrm{F}
$$

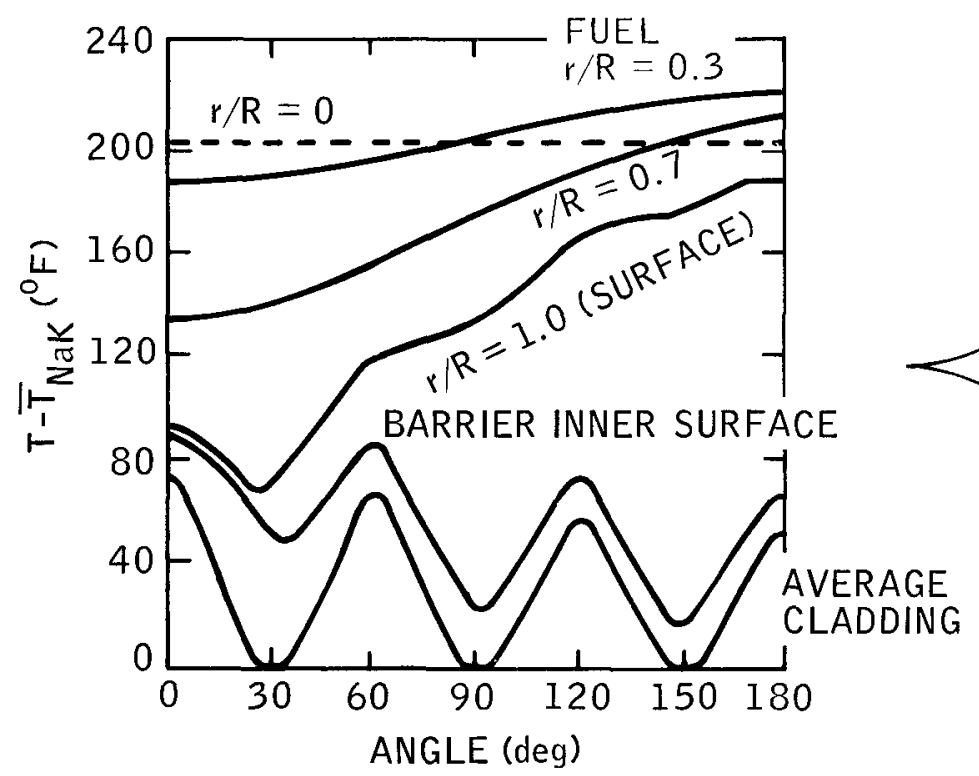

6-29-66 UNC

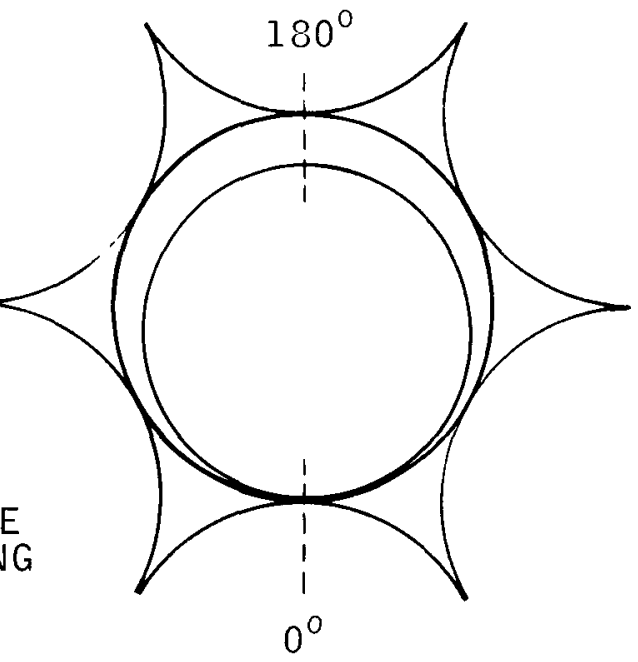

$7568-03286$

Figure 16. Temperature Distributions for S8DR Asymmetric Fuel Rod

NAA -SR - 12482 


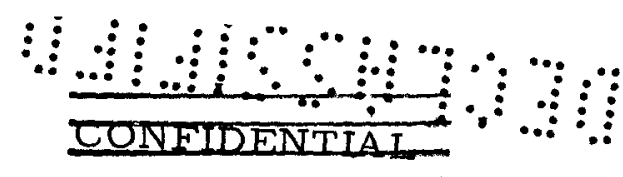

\section{E. STRESS ANALYSIS}

As a result of the large number of cracks in the cladding of the S8ER fuel elements, a detailed reanalysis of both the steady state and transient stresses in the S8DR cladding was performed. In connection with this effort, an evaluation was also performed to determine the possible advantages which might be realized from using $15-\mathrm{mil}$ thick Hastelloy $\mathrm{N}$ cladding rather than the reference 10-mil thick Hastelloy N.

In general, the cladding can be divided into two regions, each having characteristically different stresses. The center region of the tube has relatively high sustained stresses during operation but is little affected by transients. In the region near the end caps, the sustained stresses are low, but the transient or cyclic stresses are significant. In addition, to complete the analysis of the cladding stresses, it was necessary to add the appropriate fabrication and as sembly stresses to the ope"ating stresses.

Steady state operating stresses in the cladding are the result of the axial, circumferential, and radial temperature distributions in the cladding. They also arise because of the difference between the external NaK pressure and the fuel element internal pressure (due to hydrogen dissociation of the fuel and fission gas release).

As noted in Figure 16, the circumferential temperature variation is sinusoidal around the periphery of the cladding with the cold sections corresponding to the coolant channels and the hot sections corresponding to the adjacent fuel elements. The distribution of the resultant axial stress is shown in Figure 17. The magnitude of the circumferential temperature variation is a function of the local power generation in the fuel rod, and the temperature difference and the resultant axial stresses consequently decrease near the ends of the fuel element because of the decreased power generation. Figure 17 also shows the effect of various combinations of cladding and fuel element contact. The axial stresses due to the circumferential temperature variations are the largest component of the steady state cladding stresses.

The most significant parameter in a margin evaluation of the steady state stresses is the creep strain associated with the relaxation of the axial stress due to the circumferential temperature variation. Assuming a uniform creep

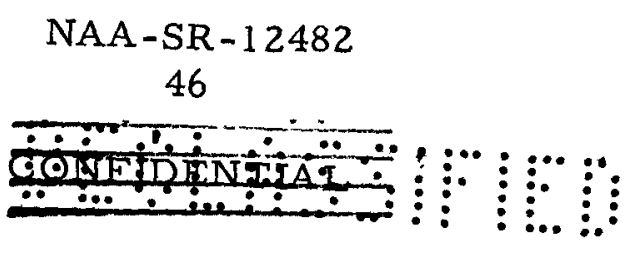




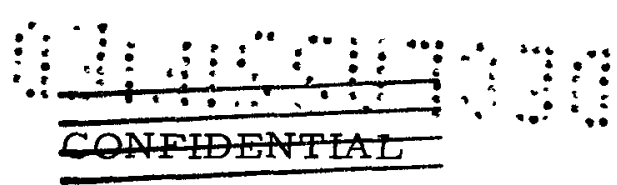

TABLE 9

CALCULATED STRESS SAFETY FACTORS

\begin{tabular}{|c|c|c|}
\hline $\begin{array}{l}\text { Stress } \\
\text { Condition }\end{array}$ & $\begin{array}{l}\text { Safety } \\
\text { Factor }\end{array}$ & $\begin{array}{c}\text { Reactor-Only } \\
\text { Test }\end{array}$ \\
\hline $\begin{array}{l}\text { Upper End } \\
\text { Stress } \\
\text { Cycling }\end{array}$ & $\begin{array}{l}\text { Stress multiplier to } \\
\text { cause fatigue failure }\end{array}$ & 18 \\
\hline $\begin{array}{l}\text { Lower End } \\
\text { Stress } \\
\text { Cycling }\end{array}$ & $\begin{array}{l}\text { Stress multiplier to } \\
\text { cause fatigue failure }\end{array}$ & 80 \\
\hline Maximum ${ }^{*}$ & $\begin{array}{l}\text { Ir radiated creep } \\
\text { strain-to-failure }\end{array}$ & \\
\hline $\begin{array}{l}\text { Compressive } \\
\text { Creep }\end{array}$ & $\begin{array}{l}\text { Creep strain from } \\
\text { relaxation }\end{array}$ & 5.9 \\
\hline Maximum ${ }^{*}$ & $\begin{array}{l}\text { Irradiated creep } \\
\text { strain-to-failure }\end{array}$ & \\
\hline $\begin{array}{l}\text { Tensile } \\
\text { Creep }\end{array}$ & $\begin{array}{l}\text { Creep strain from } \\
\text { relaxation }\end{array}$ & 5.9 \\
\hline $\begin{array}{l}\text { Creep } \\
\text { Collapse }\end{array}$ & $\begin{array}{l}\text { Pressure to cause } \\
\text { collapse in } 12,000 \mathrm{hr} \\
\quad \div \\
\text { External gage pressure }\end{array}$ & 1.5 \\
\hline
\end{tabular}

*Considers maximum octahedral shear strain

next to the upper and lower end caps to heat or cool more rapidly than the relatively massive end caps. The resulting temperature difference between the cladding and end cap causes bending stresses at the joint. Although these stresses are relatively short-lived, they may be quite significant. A detailed analysis was performed to calculate the fatigue damage fraction using the stresses calculated for each type transient and an estimate of the maximum number of times the transient could occur. The safety factor was found through iteration by determining the factor by which it would be required to multiply each stress to raise the damage fraction to 1.0 . The factors for the upper and lower ends are shown in Table 9.

Another way of summarizing the stresses is given in Table 10. The values given are the total strain induced in the Hastelloy $\mathrm{N}$ by the parameter 


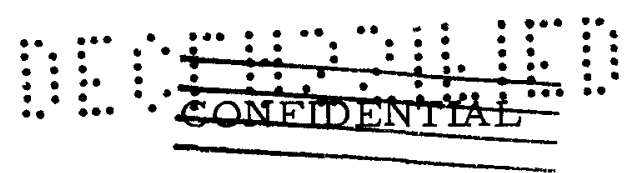

TABLE 10

SUMMARY OF STRESS COMBINATIONS

\begin{tabular}{|c|c|c|c|c|c|}
\hline \multirow{2}{*}{ Parameter } & \multicolumn{2}{|c|}{ Stress } & \multirow{2}{*}{$\begin{array}{c}\text { Worst } \\
\text { Expected } \\
\text { Case, S8DS }\end{array}$} & \multirow{2}{*}{$\begin{array}{c}\text { Total } \\
\text { Combined } \\
\text { Strain } \\
(\%)\end{array}$} & \multirow{2}{*}{$\begin{array}{l}\text { Parameter } \\
\text { Magnitude for } \\
0.1 \% \text { Strain }\end{array}$} \\
\hline & Type & Location & & & \\
\hline $\begin{array}{l}\text { Circumferential Tem- } \\
\text { perature Variation }\end{array}$ & Axial Tension & Center & $100^{\circ} \mathrm{F}$ & 0.065 & $168^{\circ} \mathrm{F}$ \\
\hline $\begin{array}{l}\text { Axial Temperature } \\
\text { Gradient }\end{array}$ & Axial Tension & $\begin{array}{l}\text { Lower } \\
\text { End }\end{array}$ & $26^{\circ} \mathrm{F} / \mathrm{in}$. & 0.023 & Large \\
\hline \multicolumn{6}{|l|}{ External Pressure } \\
\hline Long-Term & Circumferential & Entire & 43 psig & - & 61 psig $^{*}$ \\
\hline Surge & Compressive & Tube & 48 psig & - & 80 psig $^{*}$ \\
\hline \multirow[t]{2}{*}{ Cold Slug } & Axial Tension & $\begin{array}{l}\text { Lower } \\
\text { End }\end{array}$ & $200^{\circ} \mathrm{F}$ & 0.037 & $500^{\circ} \mathrm{F}$ \\
\hline & $\begin{array}{l}\text { Circumferential } \\
\text { Tension }\end{array}$ & $\begin{array}{l}\text { Upper } \\
\text { End }\end{array}$ & $200^{\circ} \mathrm{F}$ & 0.032 & $790^{\circ} \mathrm{F}$ \\
\hline $\begin{array}{c}\text { Cladding Quench (Tem- } \\
\text { perature Difference } \\
\text { Causing Interference) }\end{array}$ & $\begin{array}{l}\text { Circumferential } \\
\text { Tension }\end{array}$ & Center & $23^{\circ} \mathrm{F}$ & 0.034 & $95^{\circ} \mathrm{F}$ \\
\hline $\begin{array}{l}\text { Scram on Low Flow } \\
\text { (End Cap-Tube } \Delta T \text { ) }\end{array}$ & $\begin{array}{l}\text { Circumferential } \\
\text { Compressive }\end{array}$ & $\begin{array}{l}\text { Upper } \\
\text { End }\end{array}$ & $57^{\circ} \mathrm{F}$ & 0.051 & $150^{\circ} \mathrm{F}$ \\
\hline $\begin{array}{l}\text { Scram on Low Flow } \\
\text { (Fuel Surface Tem- } \\
\text { perature Increase- } \\
\text { Internal Pressure) }\end{array}$ & $\begin{array}{l}\text { Circumferential } \\
\text { Tension }\end{array}$ & Center & $140^{\circ} \mathrm{F}$ & 0.042 & $340^{\circ} \mathrm{F}$ \\
\hline $\begin{array}{l}\text { High Power or Tem- } \\
\text { perature Scram } \\
\text { (End Cap-Tube } \Delta T \text { ) }\end{array}$ & $\begin{array}{l}\text { Circumferential } \\
\text { Tension }\end{array}$ & $\begin{array}{l}\text { Upper } \\
\text { End }\end{array}$ & $65^{\circ} \mathrm{F}$ & 0.044 & $180^{\circ} \mathrm{F}$ \\
\hline
\end{tabular}

*Buckling Limits

listed, plus the residual fabrication stresses. The magnitude of the parameter required to produce $0.1 \%$ strain is also given to provide a frame of reference and to indicate the sensitivity of the stress level to the magnitude of the parameter. No particular significance is attributed to this strain level, though it marks the approximate end of the proportional region of stress and strain for the ir radiated Hastelloy $\mathrm{N}$ cladding. The fact that the combined stresses are all within the elastic range indicates that the Hastelloy $\mathrm{N}$ cladding should withstand the applied loads without failure.

Increasing the cladding thickness has a very minimal effect on the cladding stresses. This is because the thermal gradients are essentially the same as with 10-mil thick cladding. A significant increase in the safety factor on creep

NAA -SR - 12482

49 


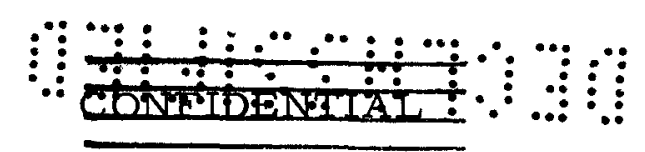

collapse would result with increased cladding thickness; the increase was not recommended, however, since the factor was considered adequate.

The other potentially advantageous reason for considering 15-mil cladding was the belief that the material properties of the 15-mil cladding might be superior to the properties of the 10-mil cladding. The basis for this assumption was the small number of metallic grains across the typical as-processed 10-mil tubing cross section, (9) and the observation that the material properties were apparently affected by the number of grains. (10) It was believed that the $50 \%$ increase in cladding thickness with the $15-$ mil cladding would possibly provide enough additional grains to improve the material properties. However, tests on both irradiated and unirradiated 10 and $15 \mathrm{mil}$ as-processed Hastelloy $\mathrm{N}$ cladding have failed to substantiate this belief.

Finally, although the safety factor on creep collapse would be improved, the increased cladding thickness would cause a small increase in the hydrogen barrier stresses. Further, the increased cladding thickness would impose a modest reactivity penalty, the ramifications of which were discussed in Section III. Consequently, there appeared to be no clear justification for increasing the cladding thickness to 15 mils.

At the conclusion of Phase I of the study, it was clear that the 0.010 -in. thick cladding was adequate to withstand all stresses introduced by nuclear operation.

NAA-SR - 12482

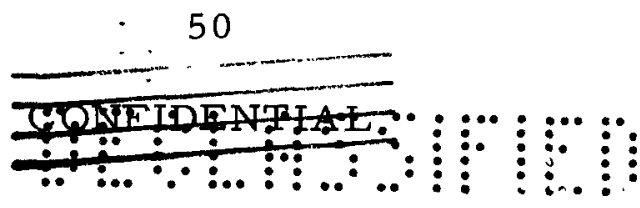




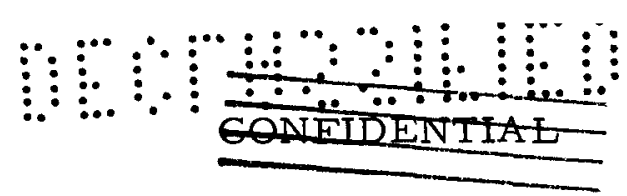

\section{PHASE II RESULTS}

\section{A. GROUND RULES FOR PHASE II}

The following items specifically applied to Phase II of the study:

1) The revised upper limit linear swelling correlation was to be used

2) Core vessel ID could be changed, but the OD was to remain unchanged

3) Only 11.3-mil thick Hastelloy $\mathrm{N}$ cladding was considered (nominal $10 \mathrm{mil}$ tubing)

4) Coolant flow profiles which would maximize phase change lifetime or minimize peak cladding temperature were to be considered

5) The use of a symmetrical hexagonal fuel array was not a fixed requirement

6) Statistical evaluations of the fuel-cladding contact probability and fuel element failure probability were to be performed

7) Evaluation of alternate fuel element end caps was to be made

8) Reference phase change and reactivity loss calculations were to be performed using a fuel thermal conductivity of $10.0 \mathrm{Btu} / \mathrm{hr}-\mathrm{ft}-{ }^{\circ} \mathrm{F}$.

It was decided to use a more realistic value for the fuel thermal conductivity for Phase II of the trade study. As mentioned in Section VI, the value of $7.5 \mathrm{Btu} /$ $\mathrm{hr}-\mathrm{ft}-{ }^{\circ} \mathrm{F}$ which was used in Phase I of the study was extremely conservative. The value of $10.0 \mathrm{Btu} / \mathrm{hr}-\mathrm{ft}-{ }^{\circ} \mathrm{F}$ which was used in Phase II of the study still appears conservative and is below the tentatively recommended value of 12.0 to 13.0 Btu $/ \mathrm{hr}-\mathrm{ft}-{ }^{\circ} \mathrm{F}$ for SNAP 8 fuel at operating temperature and S8DR hydrogen concentrations. (11) It was, however, considered a good lower limit value for irradiated SNAP fuel at operating temperature prior to the occurrence of beta phase change.

The heat of Hastelloy $N$ tubing which will be employed to manufacture the fuel cladding for S8DR has a nominal thickness of $11.0 \mathrm{mils}$ in the as-received condition. (The cladding diametral dimension specification was $10 \begin{array}{r}+2 \\ -0\end{array}$ mils.) 


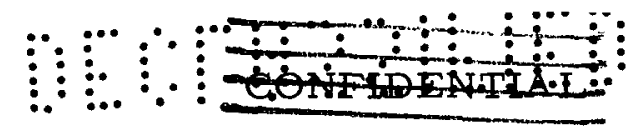

element-to-element pitch, new grid plates would be required, plus an increase in the reactor vessel ID. The feasibility of increasing the ID of the two fabricated S8DR vessels was investigated and found to be acceptable even if the system design pressure were maintained at 50 psia. A slight modification to the vessel top head would be required, however, so that the thinnest part of the vessel wall occurs below the upper grid plate. The vessel temperature in the region below the grid plate is approximately $50^{\circ} \mathrm{F}$ cooler than the mixed mean outlet temperature.

As noted in Section VI-A, it is necessary to reduce the number of fuel elements to 199 if a variably spaced (fuel elements) configuration is used while maintaining the basic hexagonal fuel array (i.e., a rod-centered array). It was found that a fuel configuration which employed more than 199 elements, but less than 211 elements, could be used for the variably spaced core. However, it required the use of a triangular pitch, coolant channel centered, fuel array, and an increased core vessel ID. This proposed fuel array contained 207 fuel elements, with the reactor vessel requiring reduction of the amount specified in Table 11. It did make the option of the variably spaced core much more attractive as a means of attaining the improved coolant flow profile.

\section{B. COOLANT FLOW PROFILE}

As noted in Section VI, results have shown that an increase in the fuel operating lifetime before the appearance of beta phase fuel material is possible by changing the coolant flow profile. It is also of importance to reiterate that beta phase change was calculated to first occur in Ring VIII of the fuel elements with the previously specified S8DR flow baffle. The first appearance of beta phase fuel in the central portions of the core where there are fewer fuel elements would appear desirable.

It also appears desirable, from considerations of cladding material properties and stresses, to keep the peak cladding temperature nearly uniform across the core radius. A flow profile which provided minimum peak cladding temperatures would also provide peak fuel temperatures which were much more nearly uniform than provided by the previously specified S8DR flow baffle. Previous studies have indicated that maximum phase change lifetime is achieved when the peak fuel temperature is uniform.

NAA -SR - 12482

53

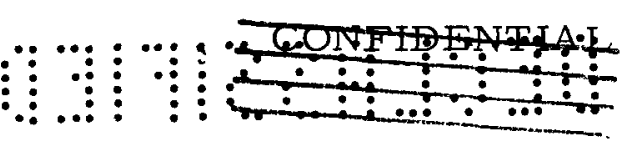




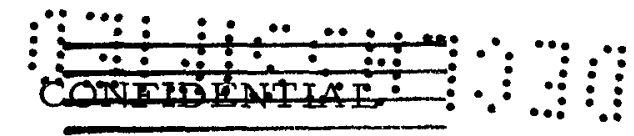

Studies were performed in which the performance characteristics of cores with the previously specified S8DR flow baffle and with optimized flow profiles were compared. The final optimized flow profile was chosen to approach the uniformly minimum cladding temperature profile since it was determined that only a small difference existed in the phase change lifetimes for the two optimized flow profiles. These studies have shown that, relative to the previously specified S8DR baffle, the optimized flow profile provides the advantages listed below.

1) Reduction of $50^{\circ} \mathrm{F}$ in the maximum beginning-of-life cladding temperatures,

2) Increase of approximately $10 \%$ in the phase change lifetime,

3) Increase of $35^{\circ} \mathrm{F}$ in the peak beginning-of-life fuel temperature, but a reduction of $15^{\circ} \mathrm{F}$ in the peak end-of-life fuel temperature, and

4) Peak end-of-life fuel temperatures which are nearly uniform.

A comparison of beginning- and end-of-life ( $\sim 18$ months operation) peak fuel and maximum cladding temperatures for the two flow profiles as a function of core position is shown in Figures 18 through 21. The maximum cladding temperatures shown are for touching fuel elements and include the effect of the circumferential temperature ripple in the cladding. The data are plotted as a function of the normalized radius squared to indicate approximately the number of fuel elements at a given temperature.

The primary cause of the temperature profile shift during lifetime is the motion of the control drums. The control drum motion, required to compensate for reactivity losses during operation, causes a shift of the radial power profile. The sharp temperature drop at the outer edge of the core is caused by the bypass coolant which flows around the outside of Ring IX rather than through the central rings of fuel. The amount of bypass flow is a function of coolant velocity at the edge of the core and of the area available for flow.

As noted in Section VI-B-2, the desired flow profile could be achieved by either of two methods with a minimal perturbation to the current design. The desired flow could be achieved by redesigning the flow baffle plate or by using variable element spacing. Within the constraint of retaining the current core vessel

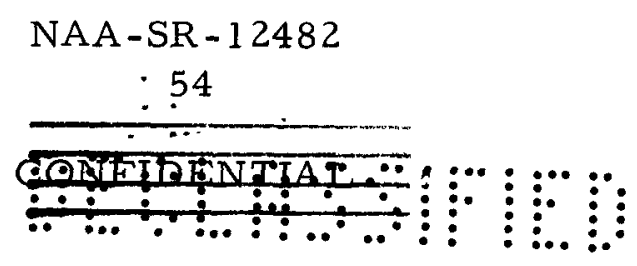



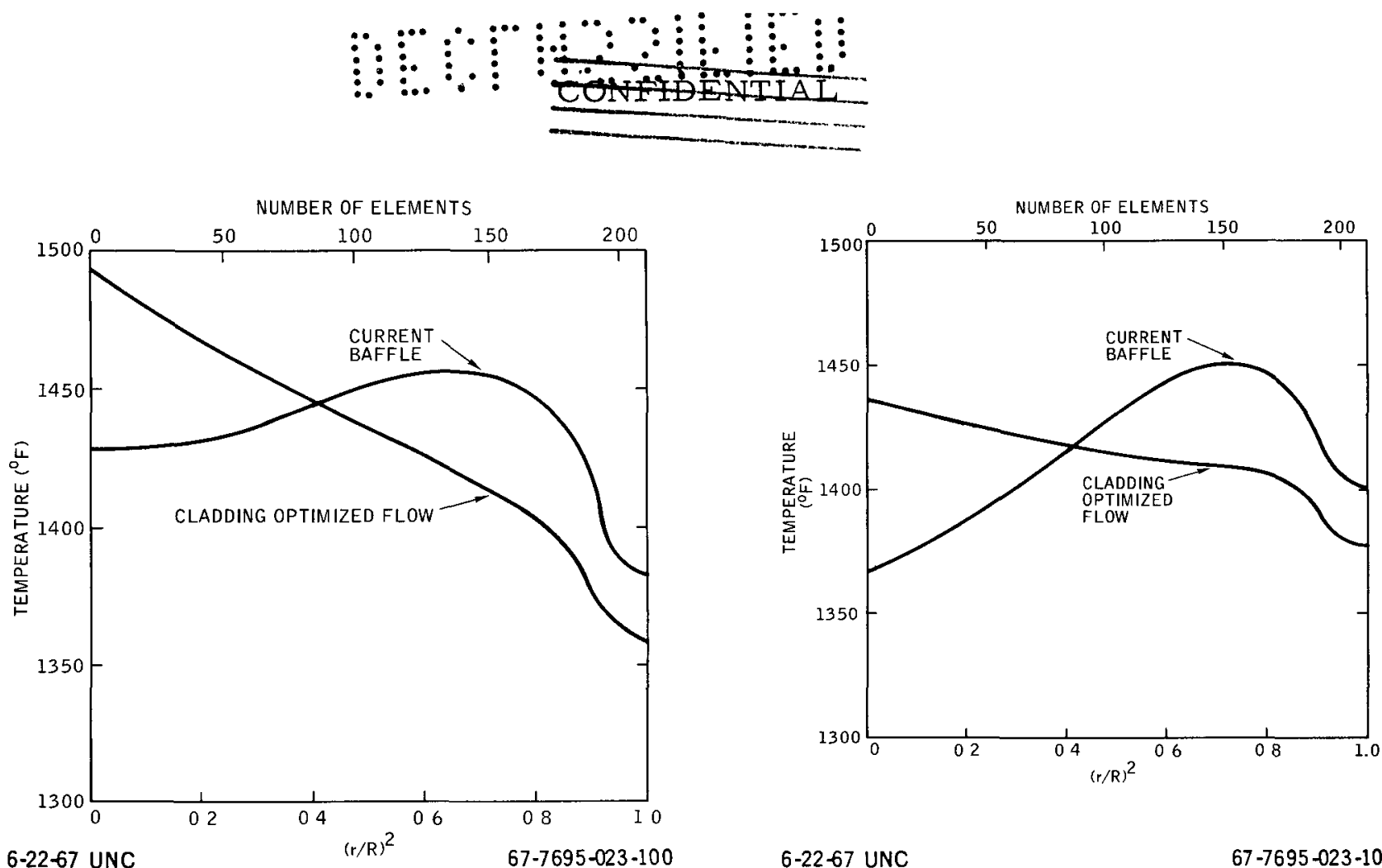

6-22-67 UNC

$67-7695-023-100$

6-2267 UNC

$67-7695-023-101$

Figure 18. S8DR Peak Fuel

Temperature Comparison

(Beginning-of-Life)

Figure 19. S8DR Peak Fuel Temperature Comparison (18-Months Operation)

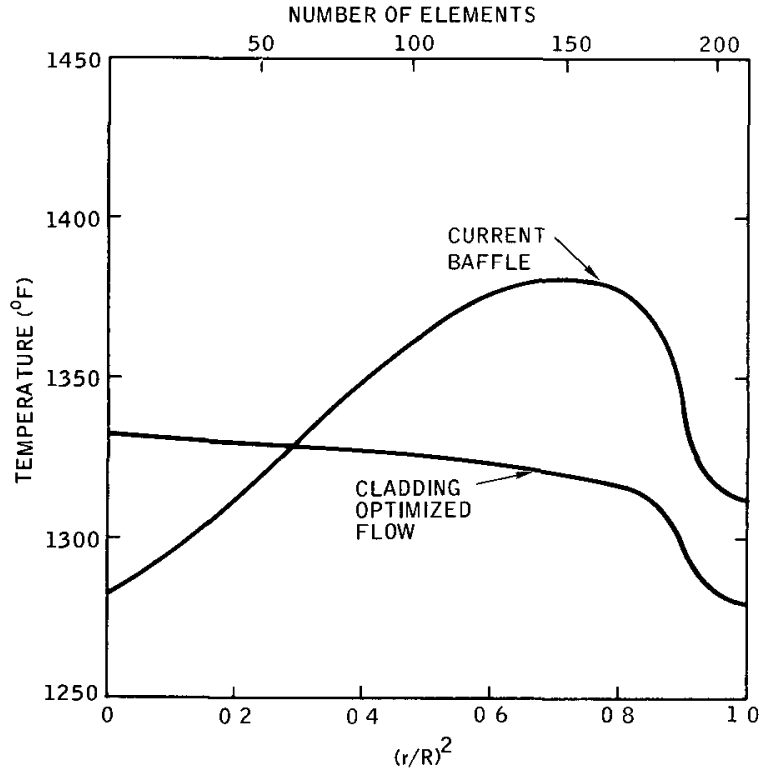

6-22-67 UNC

Figure 20. S8DR Maximum Cladding Temperature Comparison

(Beginning-of-Life)

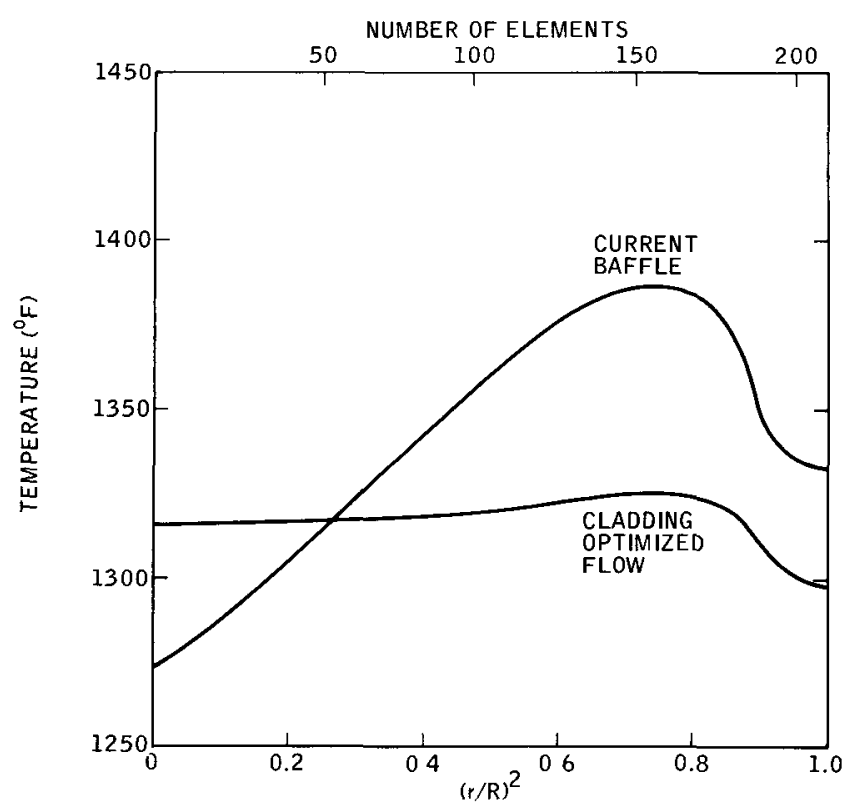

6-22-67 UNC

$67-7695-023-98$

Figure 21. S8DR Maximum Cladding Temperature Comparison (18-Months Operation)

NAA - SR - 12482 
OD, however, it would be necessary for the variably spaced core to have fewer than 211 fuel elements. The relative shapes of the coolant flow profiles at the reactor midplane for the current S8DR reference baffle and for an optimized baffle are shown in Figure 22. The flow profile for the actual optimized core would lie within the shaded areas of Figure 22.

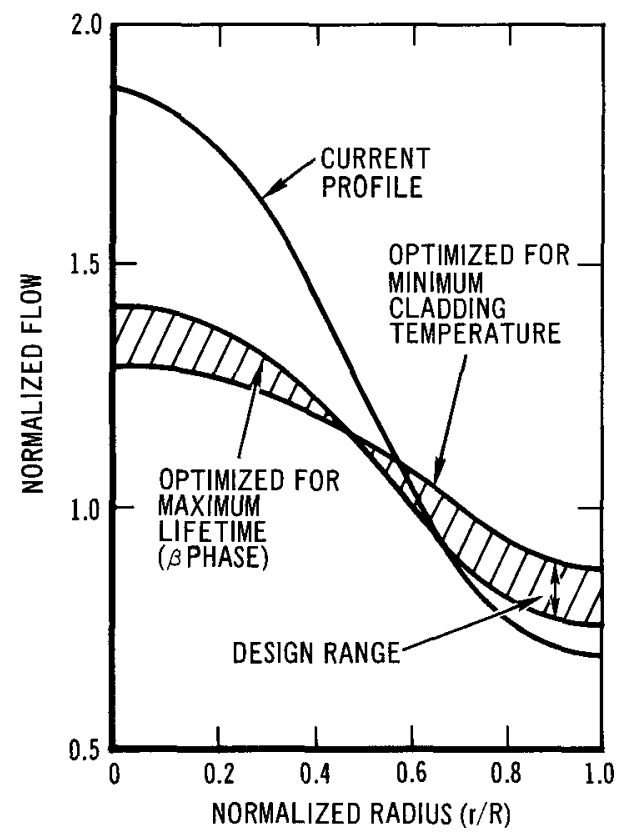

Figure 22. S8DR Trade Studies (Flow Profile at Core Midplane)

6-28-67 UNC

67-7695-023-93C

\section{GAS GAP OPTIMIZATION}

The optimization procedure was again used to size the fuel-to-cladding gas gaps based on the assumptions employed in this phase of the study. The major differences, compared to Phase I of the study, were the use of a fuel thermal conductivity of $10.0 \mathrm{Btu} / \mathrm{hr}-\mathrm{ft}-{ }^{\circ} \mathrm{F}$ and the use of the revised upper limit fuel growth correlation (see Figure 3 ). The sizing of both the diametral and the axial gas gaps in the fuel elements included factoring in of these two developments. Studies were performed to optimize the diametral gas gap for the three cores, (1) 211 elements, reference S8DR baffle, (2) 211 elements, optimized flow profile, and (3) 207 elements, optimized flow profile. Results of the optimization studies are shown in Figures 23 and 24 . The trends in the calculated fuel phase change lifetime results which were observed in Phase I of the study (Tables 4 through 7 and Figure 8 ) are also applicable to the Phase II results.

NAA -SR - 12482 


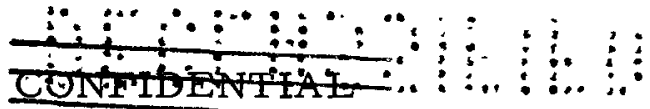

Figure 23. S8DR Lifetime vs Gap, 211 Elements, Current Baffle (600 kwt, $1300^{\circ} \mathrm{F}$ outlet)
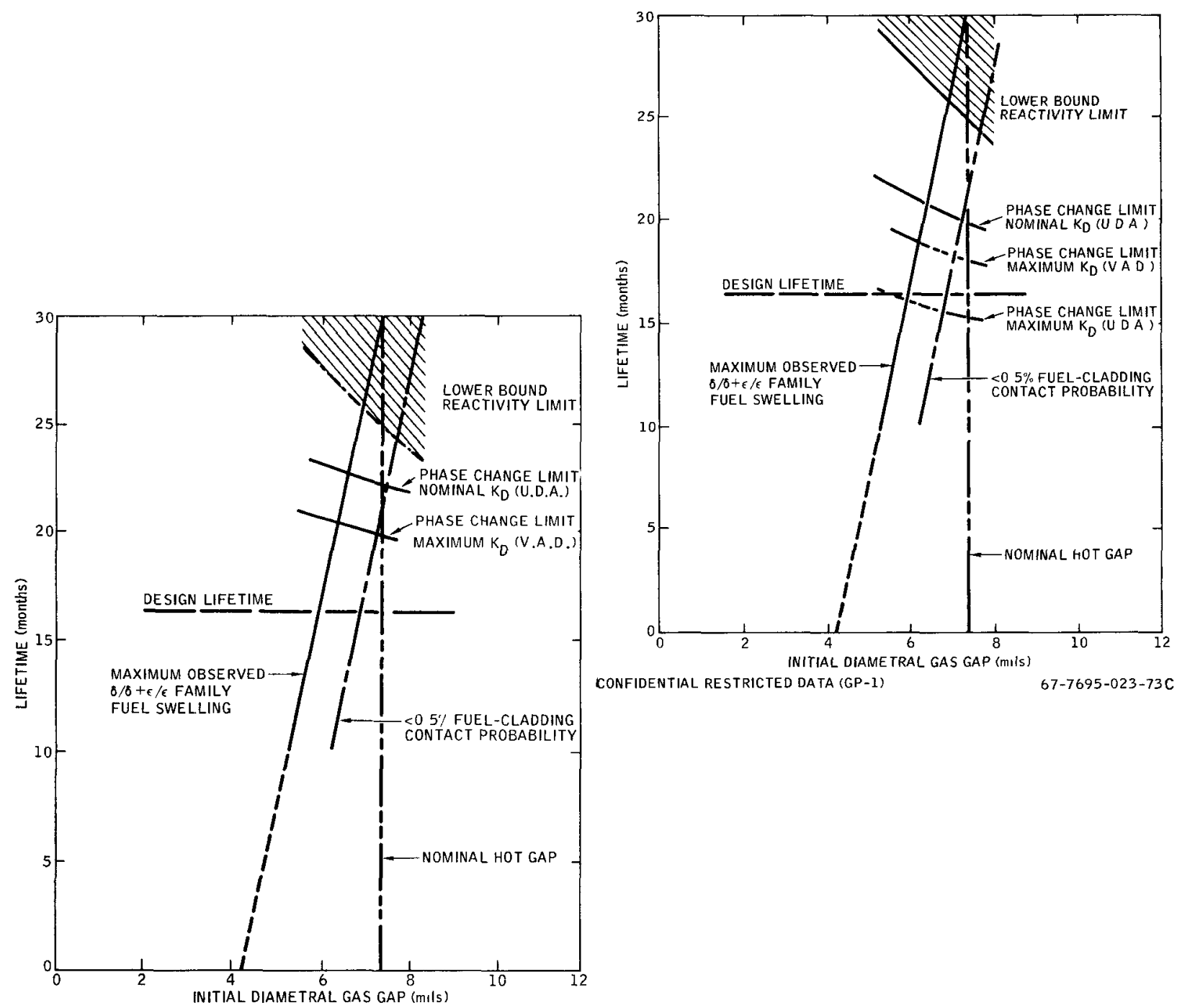

CONFIDENTIAL RESTRICTED DATA (GP-1)

Figure 24. S8DR Lifetime vs Gap, 211 Elements, Cladding Optimized Baffle (600 kwt, $1300^{\circ} \mathrm{F}$ outlet) 


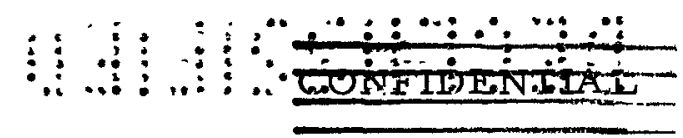

The specified fuel growth and beta phase limits are conservative as neither takes credit for the ability of the cladding to accommodate some strain before failure. Two fuel swelling limit lines are presented in Figures 23 and 24 . The swelling limit line which predicts the greater lifetime corresponds to the maximum observed unrestrained $\delta / \delta+\epsilon / \epsilon$ family of fuel swelling data. This represents the maximum expected fuel swelling for S8DR operation since beta phase fuel swelling should not occur. The lower swelling limit line in the figures corresponds to a fuel-cladding contact probability of less than $0.5 \%$, using a normal distribution to describe the spread in the fuel swelling data and the manufacturing tolerances in building the fuel elements.

The effect on the fuel phase change lifetime of changing the coolant flow profile is seen in comparing Figures 23 and 24. The designation U. D. A. refers to the conservative as sumption that the hydrogen leakage parameter, $K_{D}$, observed in isothermal tests, is uniformly applicable along the rod axis. The V.A.D. designation refers to an axially variable assignment of $K_{D}$ to end cap and tube portions of the element, based on limited axial hydrogen scan data. The only significant difference between the 211 -element optimized flow core and the 207 element optimized flow core is the shift of the reactivity limit line. It is necessary to reduce the number of fuel elements to 207 when the variably spaced core approach is used to achieve the optimized flow profile. The reduction in the number of fuel elements reduces the excess reactivity of the core by approximately one dollar, and consequently lowers the reactivity limit line. The reactivity loss is nearly the same for all three cores.

The axial gas gap has been specified on a basis which is consistent with the diametral gas gap. Sufficient axial clearance was required to as sure negligible probability of fuel-cladding contact in the axial direction. It was also necessary to maintain sufficient clearance at the end-of-life operating conditions to allow for fission gas dilution. Dilution of the low thermal conductivity fission product gases in the fuel element gas gap reduces the fuel temperatures at end-of-life. The best estimate of the axial fuel swelling expected in S8DR and the required design axial gas gap are given in Table 12.

NAA - SR - 12482

58

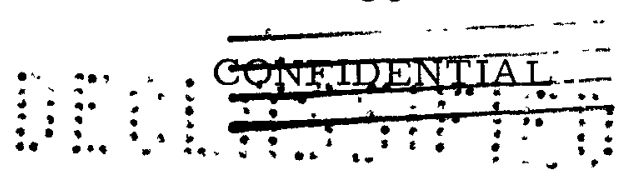




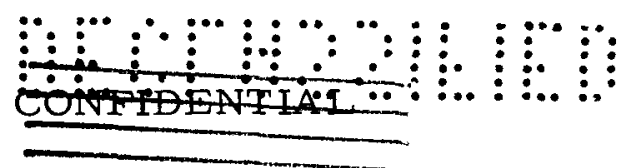

TABLE 12

S8DR AXIAL GAS GAP SELECTION

\begin{tabular}{ll}
\hline \hline Estimates of Maximum Fuel Swelling from & \\
Maximum Measured Length Changes & \\
NAA-115-1 - Sample IS-4 (Corrected to S8DR burnup) & $145 \mathrm{mils}$ \\
S8ER - Element 476 (Corrected to S8DR burnup) & 110 \\
Using upper limit swelling correlation for $\delta / \delta+\epsilon / \epsilon$ & \\
swelling over entire rod length & 170 \\
Best Estimate of Maximum Axial Swelling & 140 \\
Equivalent Gap for Fission Gas Dilution Volume & 100 \\
Recommended Axial Gas Gap & $240 \pm 30 \mathrm{mils}$
\end{tabular}

\section{REACTIVITY LIMITS}

The reactivity limits shown in the figures represent essentially a $2-\sigma$ upper limit reactivity loss value based on the 7 -element hydrogen loss test data. The expected reactivity limit is beyond the maximum lifetime plotted on the figures. The lower limit is further very conservative inasmuch as it was assumed that all fuel elements in the core would leak hydrogen at a rate equivalent to a $2-\sigma$ uncertainty on the hydrogen leakage for a single element. The hot operating reactivity losses were calculated with LOAFER and compared to the initial hot operating excess reactivity to determine the reactivity limits.

The cold-wet-poisoned excess for the S8ER was measured as $\$ 10.25$ at $275^{\circ} \mathrm{F},{ }^{(12)}$ corresponding to $\$ 10.68$ at $70^{\circ} \mathrm{F}$. A two-dimensional transport theory calculation of the excess reactivity was made for S8ER and S8DR. The results were normalized to the measured value for the S8ER and gave a samarium poisoned excess reactivity of $\$ 14.75$ for the S8DR. The use of a differencing technique gave $\$ 14.25 \pm 1.00$ for the $S 8 D R$ cold-poisoned exces $s$ with a resulting bestestimate of $\$ 14.75 \pm 1.50$ (cold, poisoned) for S8DR.

The differencing technique is outlined in Table 13, and the reactivity change and estimated uncertainty for each of the effects is listed. The S8DR considered here has 211 elements with fuel OD of $0.530 \mathrm{in.}$ on a pitch of $0.570 \mathrm{in}$. contained in a 9.214-in. ID core vessel which has a 0.105-in. wall.

NAA - SR - 12482 


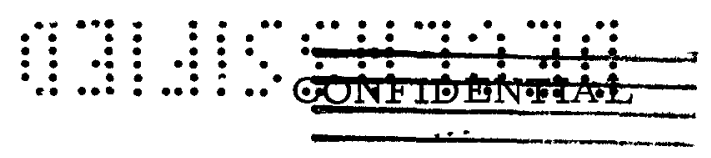

TABLE 13

S8DR EXCESS REACTIVITY

211 Elements, 5-1/8 in. Reflector

Cold Poisoned

\begin{tabular}{ll}
\hline \hline Wet Excess of S8ER & $\$ 10.68 \pm 0.50$ \\
Shave fuel to $0.530 \mathrm{in.}$ & $-0.70 \pm 0.30$ \\
Add length $14 \mathrm{in}$. to $16.825 \mathrm{in}$. & $+4.85 \pm 0.75$ \\
Add hydrogen 5.95 to $6.05 \mathrm{~N}_{\mathrm{H}}$ & $+1.00 \pm 0.10$ \\
Add prepoison $\$ 2.72$ to $\$ 3.00$ & $-0.28 \pm 0.30$ \\
Add uranium $10 \mathrm{wt} \%$ to $10.5 \mathrm{wt} \%$ & $+0.20 \pm 0.05$ \\
Change internal reflectors & $-0.50 \pm 0.10$ \\
Change cladding thickness & $-0.50 \pm 0.10$ \\
Change vessel-reflector gap & $-0.50 \pm 0.10$ \\
Wet Excess of S8DR (\$3.00 prepoison) & $\$ 14.25 \pm 1.00$ \\
\hline
\end{tabular}

As may be noted from Figures 23 and 24, the recommended nominal design diametral gas gap dimension has been specified as 7.4 mils (hot). (This corresponds to 7.0 mils in the cold, as-built condition.) The 7.4-mil hot gap represents an increase of $1.0 \mathrm{mil}$ in that dimension over the previous specification. Since it is desired to maintain the present cladding ID, the extra 1.0-mil clearance between the fuel and the cladding must be obtained by reducing the fuel rod $O D$. It will also be necessary to increase the core vessel ID by reducing the vessel wall thickness in order to maintain the minimum element-to-element spacing of 10.0 mils. Finally, if the variably spaced core were employed, it would be necessary to remove four fuel elements to obtain the optimized flow profile. The estimate of the initial excess reactivity of the 207-element variably spaced core is shown in Table 14.

The estimated reactivity losses for the three cores considered, and their associated uncertainties, are shown in Tables 15 and 16 . It is readily apparent that the largest uncertainty is associated with the calculations of the hydrogen loss. The current estimations of the hydrogen loss are based on the endurance testing of seven developmental S8DR fuel elements. The total reactivity losses for the 211-element core with the optimized flow profile are essentially the same as for the core with the previously specified flow profile even though there is an appreciable difference in the calculated phase change lifetimes.

NAA-SR - 12482

60

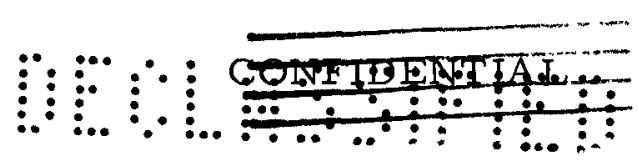




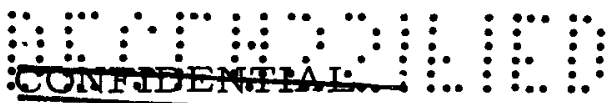

TABLE 14

S8DR EXCESS REACTIVITY

207 Elements, 5-1/8 in. Reflector Cold Poisoned

\begin{tabular}{ll}
\hline \hline Excess Reactivity (Current Core, 21l Elements) & $\$ 14.75 \pm 1.50$ \\
Remove four elements & $-1.20 \pm 0.10$ \\
Variable spacing & $-0.30 \pm 0.15$ \\
Change internal reflectors & $+0.30 \pm 0.50$ \\
Shave vessel wall & $+0.30 \pm 0.15$ \\
Excess Reactivity, 207 Elements & $\$ 13.85 \pm 1.60$ \\
\hline
\end{tabular}

TABLE 15

S8DR REACTIVITY

211-Element Cores

Cold Poisoned Excess

Power defect, xenon, and hydrogen redistribution

Shave fuel from 0.530 to 0.529 in.

Beginning-of-Life, Hot, $600 \mathrm{kwt}$, Excess

Reactivity Losses at 12,000 Hours

Fission products and burnup

$\mathrm{H}_{2}$ leakage

Samarium Prepoison Burnout

Net End-of-Life Hot Excess
$\$ 14.75 \pm 1.50$

$-3.75 \pm 0.25$

$-0.35 \pm 0.15$

$\$ 10.65 \pm 1.55$

$-2.85 \pm 0.20$

$-5.15 \pm 1.90$

$+2.90 \pm 0.10$

$\$ 3.10$ to $\$ 8.00$

NAA - SR - 12482

61 


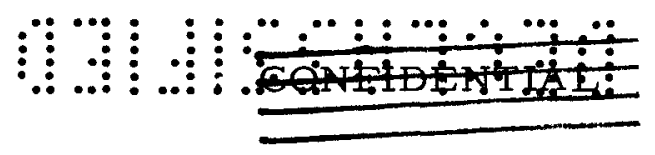

TABLE 16

S8DR REACTIVIT Y

Proposed Variably Spaced 207-Element Core

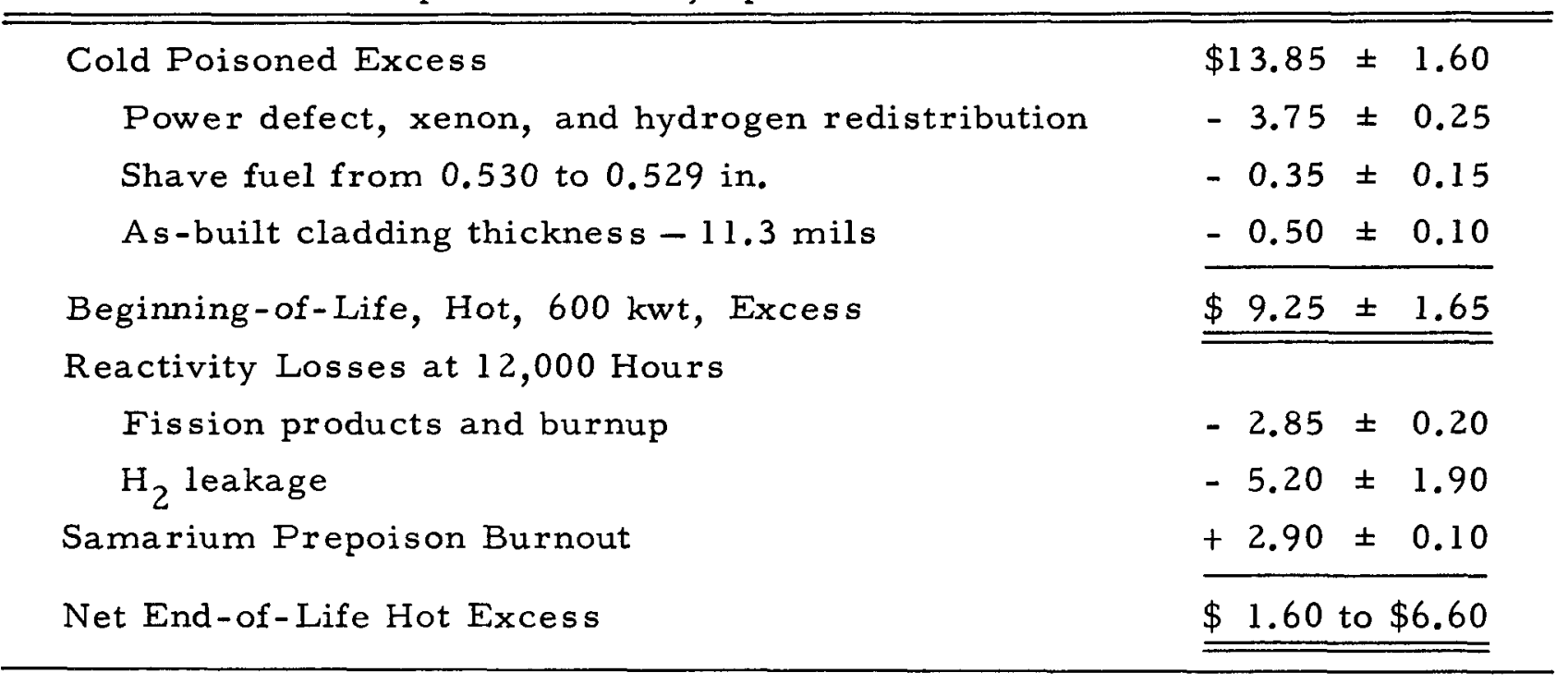

The data showing the average hydrogen barrier effectiveness through 9200 hours of endurance testing plus thermal cycle and ramp heat inputs were shown in Figure 1. The dashed line in the figure represents the extrapolation which was made with only about 3500 hours of data. The current data appear to support the extrapolation. Only the average of the 7-element data is shown in the figure. The spread in the data was used to estimate the spread in the hydrogen leakage expected from the core. For the purpose of calculating the uncertainty of the reactivity loss, the pessimistic assumption was made that the whole core would leak hydrogen at a rate characteristic of the 2- $\sigma$ uncertainty on the individual element hydrogen loss rate. It was also assumed that the hydrogen leakage was uniform axially along the length of the element. Both of these assumptions are considered very conservative. The current reactivity loss calculations were made using a fuel thermal conductivity of $10 \mathrm{Btu} / \mathrm{hr}-\mathrm{ft}-{ }^{\circ} \mathrm{F}$.

The end-of-life uncertainty values were obtained by taking the square root of the sum of the squares of the individual uncertainties. This procedure is applicable only if it is assumed that the variables whose standard deviations are so combined, are independent, i.e., orthogonal to each other. This appears to be a very good assumption since the initial excess reactivity is independent of the various reactivity loss mechanisms, and the hydrogen los is independent of 


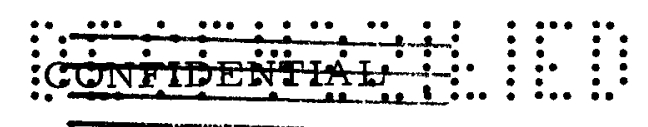

the flux-dependent reactivity losses. The fission product accumulation and fuel burnup, the prepois on burnout, the changes in the cladding thickness and fuel rod $O D$, and the short-term reactivity losses all have relatively small reactivity uncertainties. Even if the assumption of orthogonality did not hold for these items (and it appears to be a good assumption even for them), the effect on the calculated total uncertainty would be very small.

The lower limit excess reactivity values (upper limit reactivity losses) were used to obtain the reactivity limit lines shown in Figures 23 and 24 . Even with the pessimistic reactivity loss values, there is sufficient excess reactivity to operate well beyond the 12,000-hr design point, and also to exceed the swelling limit and the phase change limit.

The expected reactivity losses for S8DR with the optimized coolant flow profile are shown in Figure 25. The calculation is based on a fuel thermal conductivity of $10 \mathrm{Btu} / \mathrm{hr}-\mathrm{ft}-{ }^{\circ} \mathrm{F}$, a nominal 7.4-mil (hot) diametral gap, and the nominal $K_{D}$ with uniform axial defect constant. The associated available hot operating excess reactivity is $\$ 10.65 \pm 1.55$ (see Table 15). It is noted that the figure shows the hot, operating reactivity losses and does not include the reactivity losses from the temperature and power defects, hydrogen redistribution, and xenon buildup.

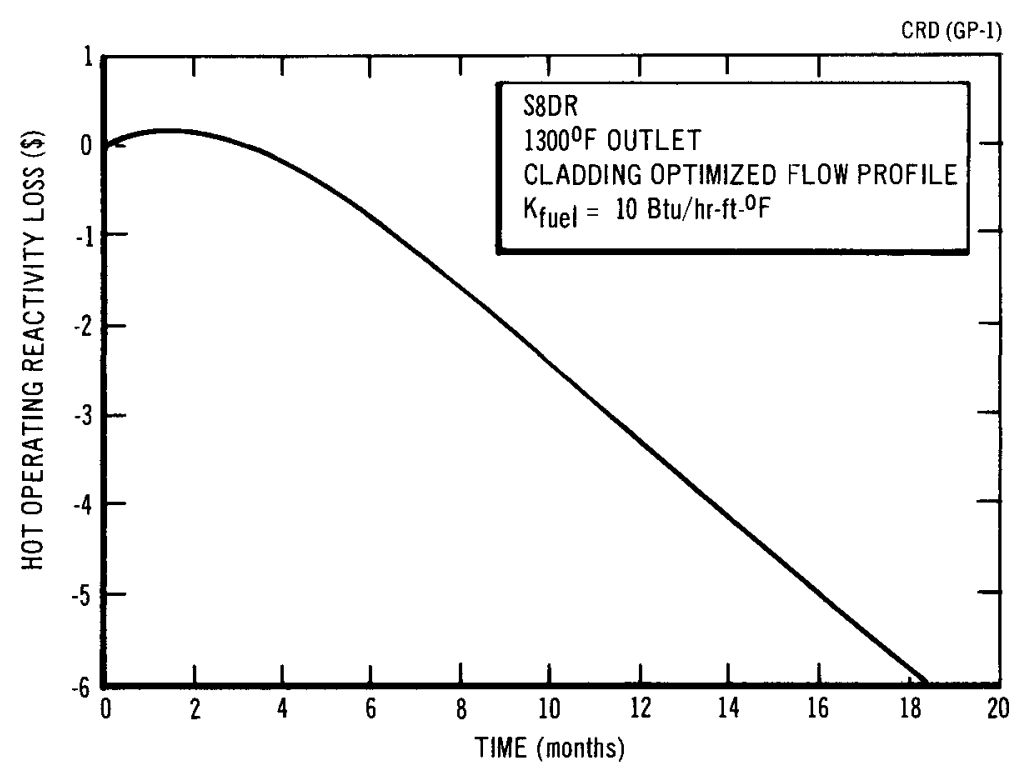

6-22-67 CRD (GP-1)

$7568-5514$

Figure 25. Predicted S8DR Reactivity Loss vs Time

NAA - SR - 12482

63 


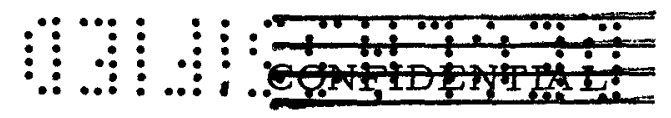

\section{E. STRESS ANALYSIS}

A significant refinement was made in the calculation of stresses during Phase II of the study. Continued concern over the adequacy of the creep collapse calculation and the oversimplification of thermal gradients employed in Phase I prompted these refined calculations. Also, the alternate end cap designs shown in Figures 26 and 27, were studied in an attempt to increase the design margin on fatigue failure.

Refined calculations of the steady-state thermal stresses in the cladding tube, and the phenomenon of creep collapse of the tube, were made using the analytical model pictured in Figure 28. The standard equilibrium shell equations were solved to balance the shell after imposition of thermal strains and, then, after small finite time steps during which creep strains were introduced at each node. These creep strains were calculated considering the stress and temperature at each node at the beginning of the time step.

The refined calculation allowed a much more precise determination of the time for creep collapse to occur or the pressure to cause creep collapse in 12,000 hours, and allowed a quantitative determination of the preferential creep strain in the hot strip. This latter factor is reflected as a relatively higher safety factor on tensile creep (occurring in the cold strip) over the safety factor on compressive creep. The revised safety factors are shown in Column 2 of Table 17. The more precise calculations show that the original values, calculated with a more simplified model, were conservative.

With the additional knowledge of creep collapse and its sensitivity to temperature and ovality, and because of the uncertainties of long-term creep rate data, it was concluded that additional margin was desirable. For this reason a reduction to 35 psia in the NaK pressure in the core was recommended. The increase in safety factor resulting from the pressure reduction is shown in Column 3 of Table 17 .

This method of increasing the safety factor was recommended instead of increasing cladding thickness because of the reactivity penalty associated with the larger thickness, the greater process experience with the 10-mil thick material, and the slightly smaller barrier stresses with the thinner material. Reducing the pressure would also allow an extension of life capability of the reactor for

$$
\text { NAA - SR - } 12482
$$

\section{4}

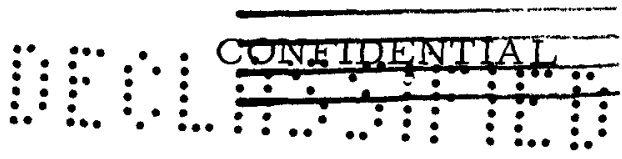




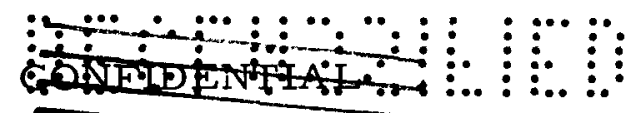

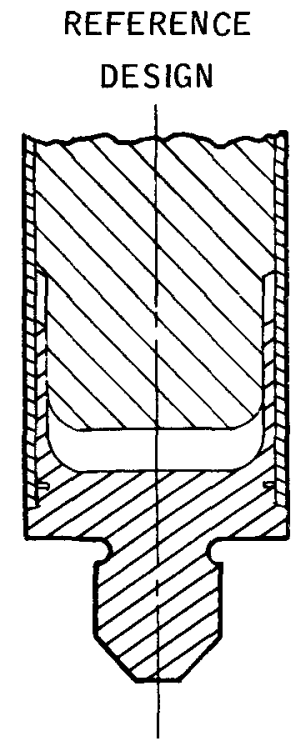

6-22-67 UNC
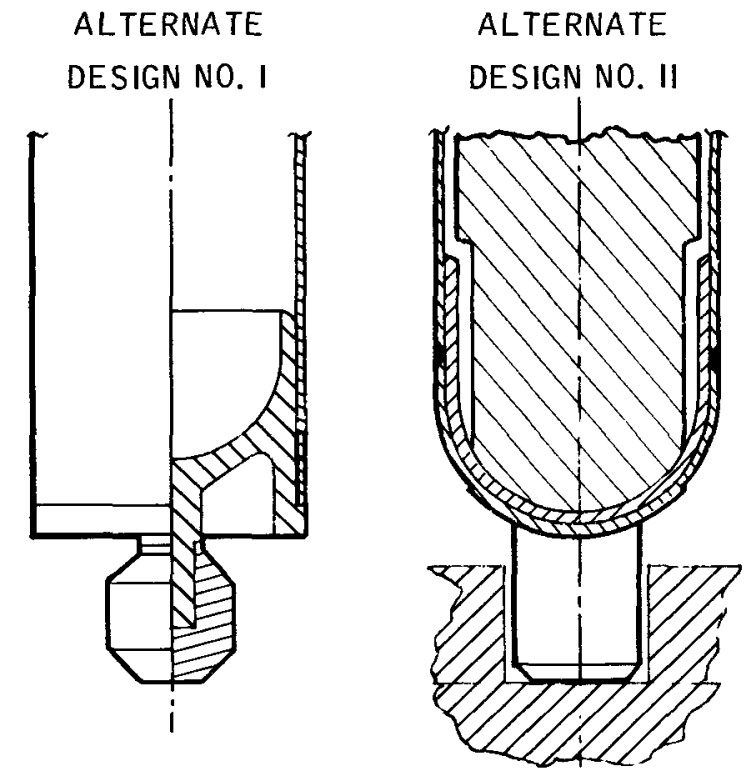

$66-7568-127-71$

Figure 26. Lower End Cap Designs

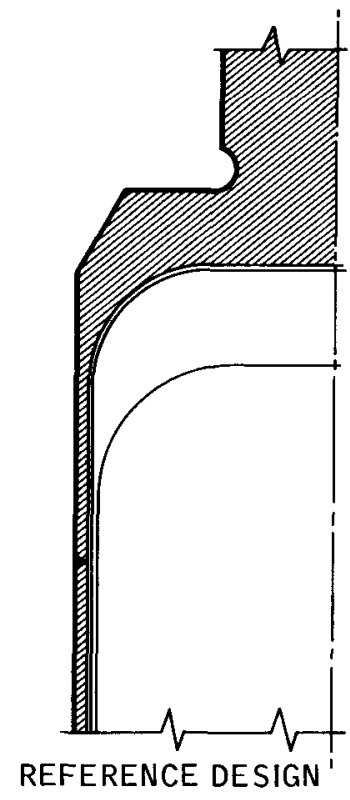

6-22-67 UNC

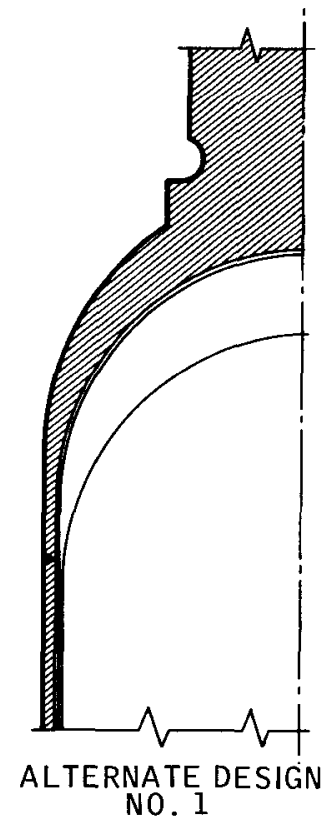

ALTERNATE DESIGN

Non

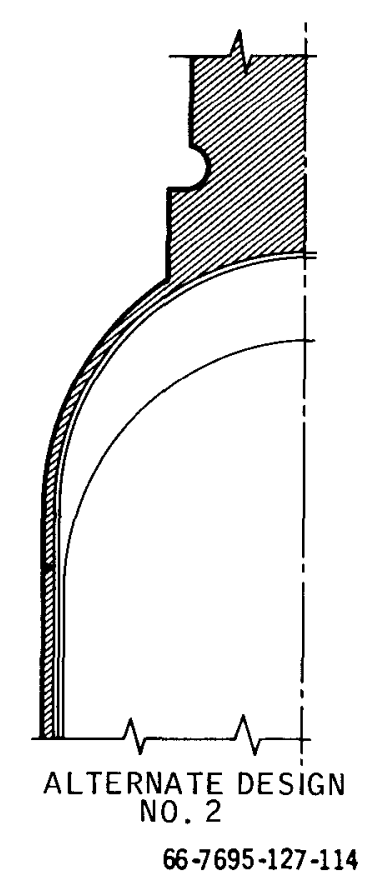

$66-7695-127-114$

Figure 27. Upper End Cap Designs

NAA-SR - 12482

65 

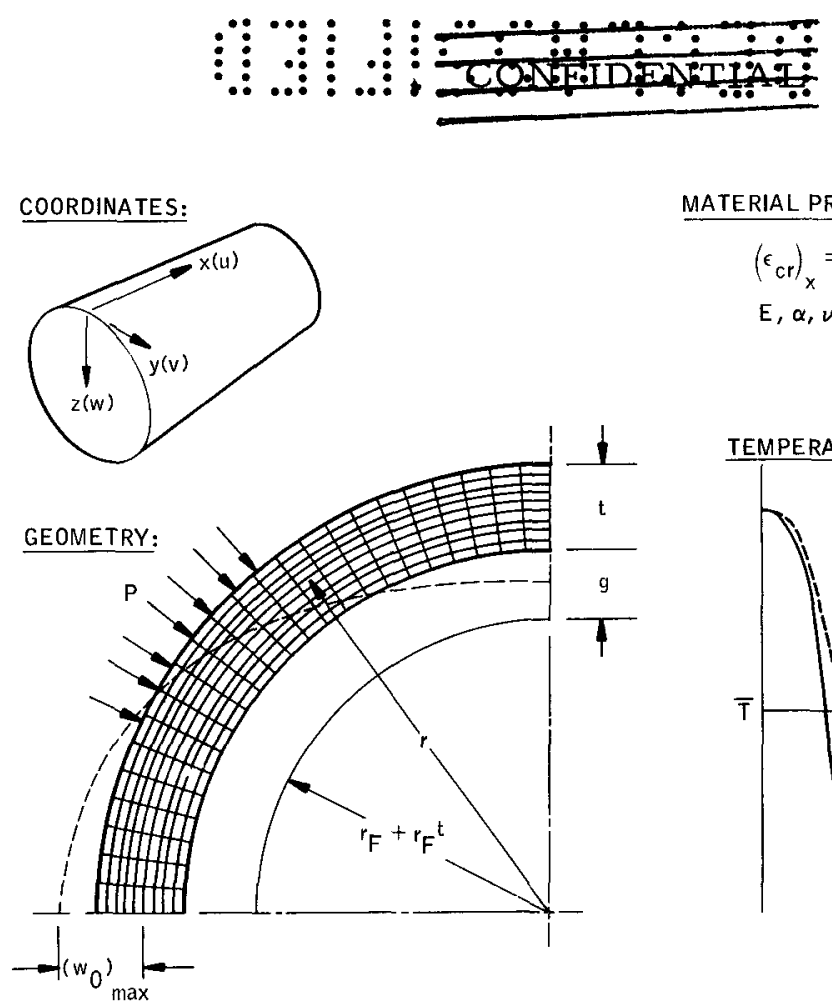

MATERIAL PROPERTIES:

$6-22-67$ UNC

$$
\begin{aligned}
& \left(\epsilon_{c r}\right)_{x}=k \sigma_{e}^{n-1}\left(\sigma_{x}-\nu_{1} \sigma_{y}\right) e^{-c / T} \\
& E, \alpha, \nu_{E}
\end{aligned}
$$

TEMPERATURE DISTRIBUTION:

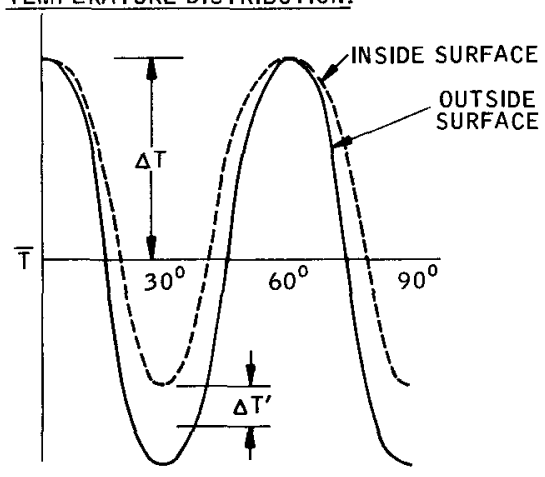

Figure 28. Creep Collapse Model

$66-7695-127-119$

\section{TABLE 17}

\begin{tabular}{|c|c|c|c|c|c|}
\hline $\begin{array}{l}\text { Stress } \\
\text { Condition }\end{array}$ & $\begin{array}{l}\text { Safety } \\
\text { Factor }\end{array}$ & $\begin{array}{c}\text { Original } \\
\text { Values for } \\
\text { Reactor-Only } \\
\text { Test }\end{array}$ & $\begin{array}{l}\text { With } \\
\text { Creep } \\
\text { Analysis } \\
\text { Results }\end{array}$ & $\begin{array}{l}\text { With Upper End } \\
\text { Modification } \\
\text { and NaK } \\
\text { Pressure Re- } \\
\text { duced to } 35 \text { psi }\end{array}$ & $\begin{array}{l}\text { With } \\
\text { Recent } \\
\text { Materials } \\
\text { Data }\end{array}$ \\
\hline $\begin{array}{l}\text { Upper End } \\
\text { Stress } \\
\text { Cycling }\end{array}$ & $\begin{array}{l}\text { Stress multiplier to } \\
\text { cause fatigue fallure }\end{array}$ & 18 & 18 & $\sim 30$ & $\sim 30$ \\
\hline $\begin{array}{l}\text { Lower End } \\
\text { Stress } \\
\text { Cycling }\end{array}$ & $\begin{array}{l}\text { Stress multiplier to } \\
\text { cause fatigue fallure }\end{array}$ & 80 & 80 & 80 & 80 \\
\hline $\begin{array}{l}\text { Maximum } \\
\text { Compressive } \\
\text { Creep }\end{array}$ & $\begin{array}{l}\text { Irradiated creep } \\
\text { strain-to-failure } \\
- \\
\text { Creep strain from } \\
\text { relaxation }\end{array}$ & $\sim 6.0$ & 6.0 & 6.0 & $6.5^{\dagger}$ \\
\hline $\begin{array}{l}\text { Maximum } \\
\text { Tensile } \\
\text { Creep }\end{array}$ & $\begin{array}{l}\text { Irradiated creep } \\
\text { strain-to-failure } \\
- \\
\text { Creep strain from } \\
\text { relaxation }\end{array}$ & 6.0 & 11.0 & 11.0 & $12.0^{\dagger}$ \\
\hline $\begin{array}{l}\text { Creep } \\
\text { Collapse }\end{array}$ & $\begin{array}{l}\text { Pressure to cause } \\
\text { collapse in } 12,000 \text { hours } \\
- \\
\text { External gage pressure }\end{array}$ & 1.5 & 1.8 & 2.8 & 2.8 \\
\hline
\end{tabular}

S8DR STRESS SAFETY FACTORS

Considers maximum octahedral shear strain

tBased on the lower 3- $\sigma$ limit for strain-to-fallure

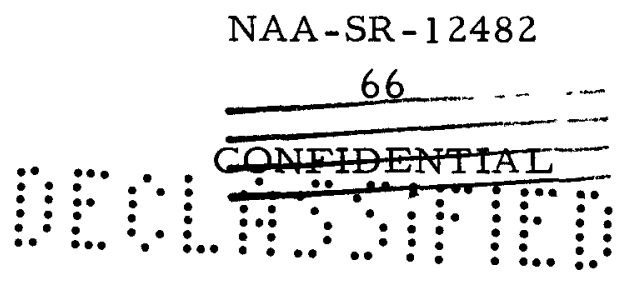




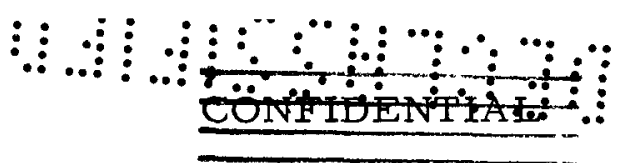

future applications with little increase in thickness. A marked increase in cladding thickness would be required at the higher pressure level in order to update the present type design to 20,000 to $40,000-\mathrm{hr}$ operation.

The study of alternate end cap designs showed that a significant increase in margin could be achieved in the upper end, the end with the lower safety factor, by changing to a spherical design as shown in Figure 27. The peak stresses during transients were reduced by about a factor of 0.6 and the safety factor was increased from 18 to about 30. No such improvement could be made in the lower end without a marked departure from earlier designs, upon which all fuel element fabrication experience is based. The safety factors, given in the third column of Table 17, are clearly adequate to cover any uncertainty in fatigue properties of the material.

Finally, with results of the creep data from the ORR S-1 Hastelloy $N$ irradiation experiment, the creep safety factors (using the lower 3-o limit) were increased slightly over the previous values. Column 4, then, of Table 17 gives the safety factors on operational stresses at the conclusion of Phase II of the study. All of these are considered very adequate for S8DR.

\section{F. STATISTICAL ANALYSIS OF FUEL-CLADDING CONTACT}

Statistical studies of the probability of fuel-cladding contact during operating life have indicated that, although the probability of fuel element failure was small for a design diametral gas gap of 6.4 mils (hot), the probability of fuel-cladding contact, based on the conservative fuel growth distribution, was higher than desired. Phase I studies, aimed at optimizing the diametral gas gap dimension, were based on a mean value for the as-built gas gap dimension and upper limit fuel swelling data. The fuel swelling limit had been arrived at by using a correlation which passed just above the applicable observed fuel swelling data. (See Figure 3, initial upper limit linear correlation.) These variables have been statistically treated in Phase II of the study.

An uncertainty in the diametral gas gap dimension exists due to the manufacturing tolerances. The only extensive data which are applicable toS8DR come from the as-built gap dimensions of the S8ER fuel rods. Although it is believed that the spread in the S8ER as-built gap was larger than would be anticipated for

NAA -SR - 12482

67

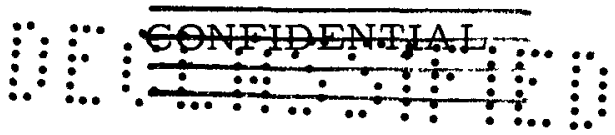


S8DR fuel elements, the S8ER data were used since no comparable data for S8DR type production fuel elements were available. The $1-\sigma$ uncertainty on the diametral gas gap for S8ER was $0.68 \mathrm{mil}$.

The largest uncertainty to be considered arises from the spread in the fuel swelling data. Extensive analyses of the available fuel swelling data have shown the primary correlation of fuel swelling with the movement of certain hydrogen concentration boundaries. This has been termed the $\delta / \delta+\epsilon / \epsilon$ family fuel swelling. The correlation is based on the results of the post-operation examination of S8ER fuel growth and on the NAA-82-1, NAA-115-1, and NAA-117-1 fuel capsule irradiation experiments. The data were for intact fuel elements in which low mechanical restraint was imposed on the fuel. Efforts continue to obtain an improved analytical expression which will be adequate to correlate all variables affecting fuel swelling. In the interim, the linear burnup correlation based on the $\delta / \delta+\epsilon / \epsilon$ family fuel swelling is being used.

The fuel swelling limit for S8DR has been defined as either (1) full diametral contact between the fuel and the cladding at any location in the core, or (2) full axial contact between the fuel and the cladding sufficient to cause axial cladding strain. Either of these conditions is indicative of incipient cracking rather than an actual breach of cladding integrity. Limited data on the strain required to produce cracking in irradiated S8DR cladding material at S8DR operating temperatures indicate that a mean additional fuel growth of approximately $1 / 2 \%$ would be required to cause cladding cracks. Additional data on the cladding strain to failure areforthcoming. In the interim, the design restraint of "no fuel swelling induced cladding strain," i. e., no fuel-cladding contact, is being used.

An example of the overlap of the fuel swelling and the diametral gap dimensions is shown in Figure 29. The effect of including the cladding strain to fracture and the effect of rejecting fuel elements with less than a minimum gas gap are also shown. As noted in the figure, this "chopped" gap distribution significantly reduces the fuel-cladding contact probability. Figure 30 shows the variation in the contact probability as a function of initial diametral gas gap for both the full gap distribution and for the chopped distribution. The chopped gap distribution has been specified for S8DR.

NAA - SR - 12482

68 


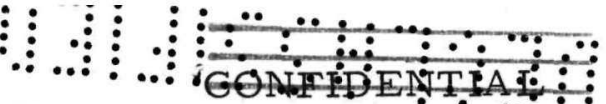

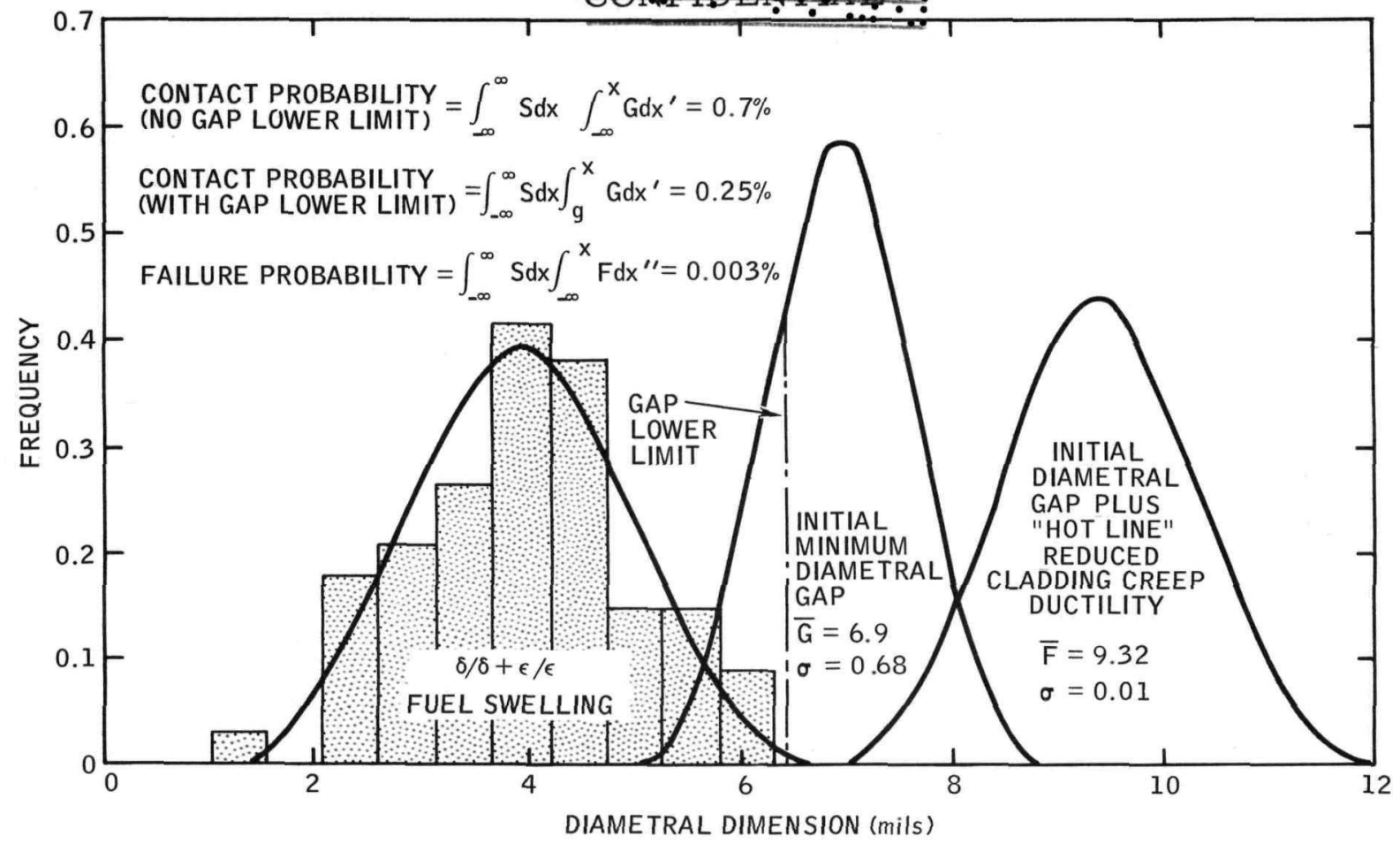

$67-7695-023-88$

CONFIDENTIAL RESTRICTED DATA (GP-1) Figure 29. Preliminary S8DR Fuel Gap
Statistical Study

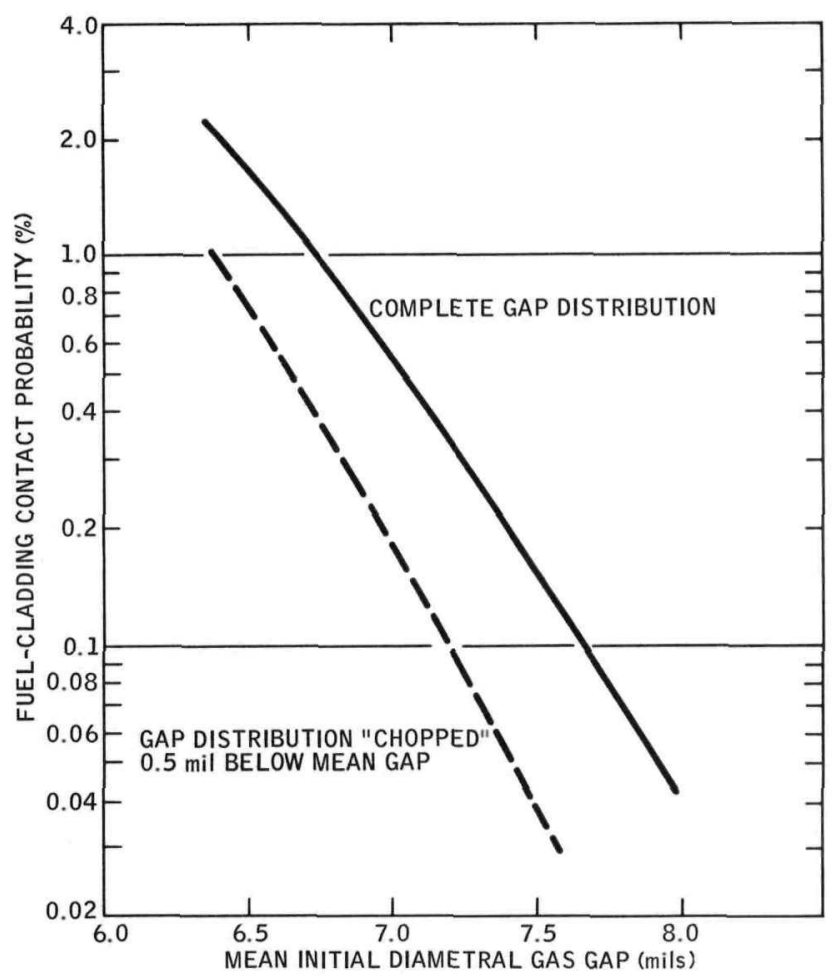

Figure 30. Fuel-Cladding Contact

Probability After 12,000-Hr Operation

6-22.67 CRD (GP-1)

$7695-5190$

NAA -SR - 12482

69

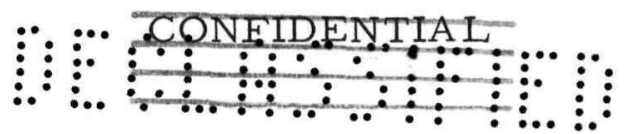


It should be noted that the 3- $\sigma$ uncertainty limit on the fuel swelling is considerably greater than any actual observed family fuel swelling. The maximum observed $\delta / \delta+\epsilon / \epsilon$ family fuel swelling falls at the $2-\sigma$ uncertainty limit as shown in Figure 31. However, several such data points at the upper side of the data distribution have the effect of spreading the uncertainty limits when a normal distribution fit to the data is used. Even with the large data spread in the swelling distribution, the probability of fuel-cladding contact is acceptably low for the proposed design diametral gas gap of 7.4 mils (hot).

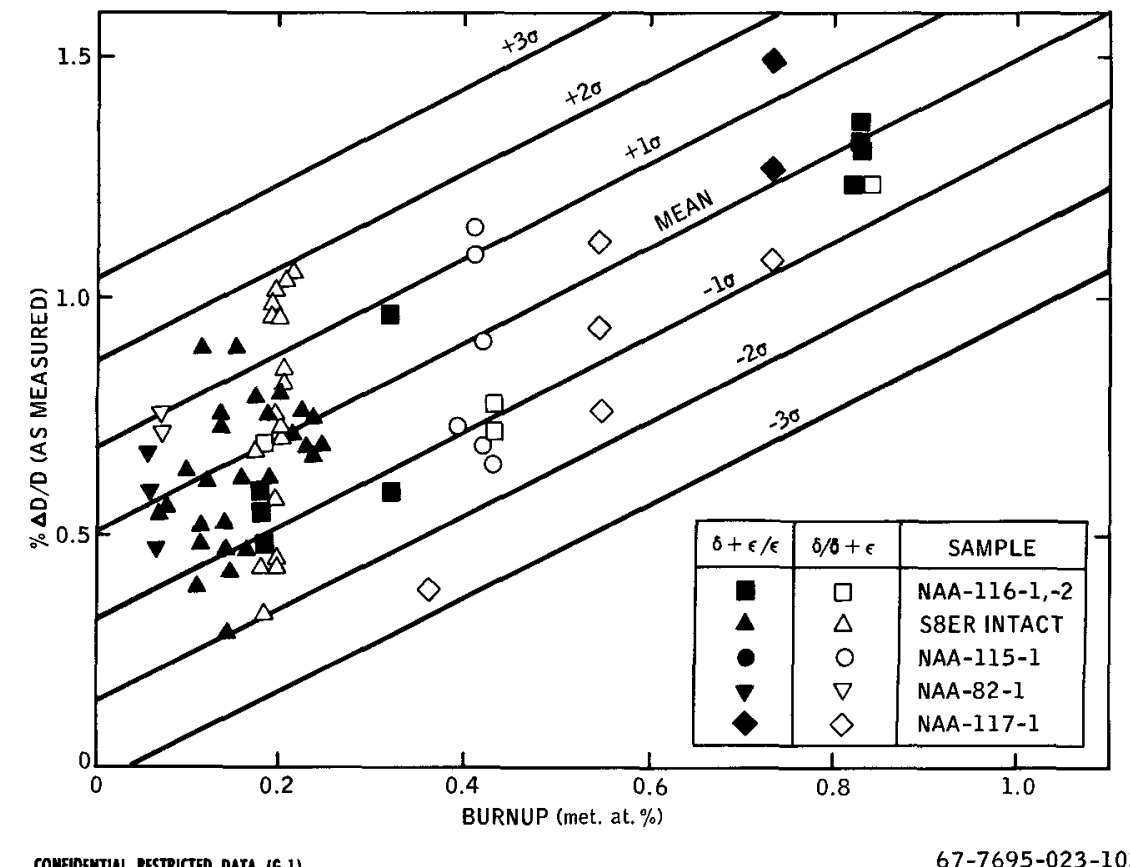

Figure 31. Fuel Growth Distribution (Samples Affected by $\delta / \delta+\epsilon$ and $\delta+\epsilon / \epsilon$ Phase Boundaries Includes NAA-116 Data)

It must also be noted that the most recent work with the fuel swelling data indicates that some temperature dependence does exist for $\delta / \delta+\epsilon / \epsilon$ fuel growth. This may be seen by observing that the data above the mean are generally hightemperature, high-carbon points, whereas those below the mean are generally lower-temperature, intermediate-carbon points. Thus, use of a statistical approach, which predicts fuel growth well in excess of the observed growth, to determine the fuel swelling limits should provide adequate conservatism with regard to any anticipated temperature-dependent correlation developed subsequent to the correlation used in this study.

$$
\text { NAA-SR - } 12482
$$




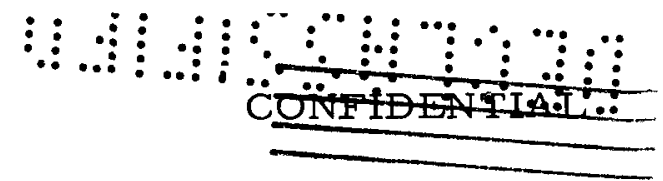

\section{CONCLUSIONS AND RECOMMENDATIONS}

The reanalysis of the S8DR reactor revealed one serious deficiency and several areas in which the design margin could be appreciably improved without inflicting serious delays in the production schedule. The recommended changes are summarized in Tables 18 and 19.

TABLE 18

SUMMARY OF RECOMMENDATIONS

S8DR Fuel Element

New Upper End Cap - Modify Fuel Rod
Modified Lower End Cap - Modify Fuel Rod
Increase Axial Clearance to $0.240 \mathrm{in.}$
Reduce Fuel Rod Diameter by $0.001 \mathrm{in.}$ to Provide $0.0065 \mathrm{in.}$
$\quad$ Minimum Diametral Clearance
Retain $11.3-$ mil Wall Thickness
Use Hastelloy N Heat Number $281-4-0143$

TABLE 19

SUMMARY OF RECOMMENDATIONS

S8DR Core

Increase Minimum Element Spacing from 7.4 mils to 10 mils

Retain Uniform Core Concept - 211 Elements

Alter Flow Profile to Approach that Required for Minimum Cladding Temperature/Maximum Life

Add Flow Distribution Ring in Lower Plenum

Conduct Design Verification Hydraulic Test

These Requirements Require:

New grid plates, baffle plate, and flow distributor

Machining of the vessel, ID

Reduction of operating pressure (35 psi)

The area of serious deficiency was the previously specified axial gas gap of 86 mils. As may be noted from Table 12, the maximum expected axial grow th 
is of the order of 110 to 170 mils. Under the constraints of no cladding strain caused by fuel growth, the axial gap was inadequate. The recommended gap of 240 mils allows sufficient room for fuel growth as well as space for dilution of the fission gas which accumulates in the gap.

The previously specified diametral gap of 6.4 mils (hot) appeared to be adequate to allow 12,000 hours operation when the maximum observed fuel swelling limit was employed to optimize the gap. However, a statistical evaluation of the fuel growth and the gap dimensions indicated that the probability of fuel-cladding contact was greater than desirable. The average fuel-cladding contact probability was calculated to be approximately $2 \%$. It was considered necessary to keep the fuel-cladding contact probability to less than $0.5 \%$. The recommended production specification has specified an average minimum diametral gap of 6.5 mils (6.9 mils hot) with an absolute minimum of 6.0 mils $(6.4 \mathrm{mils}$ hot $)$ in the highburnup, high-temperature portion of the fuel element. The nominal cold gap over that portion of the fuel element is $7.0 \mathrm{mils}(7.4 \mathrm{mils}$ hot $)$. The local minimum gap distribution has effectively been chopped or truncated at a value 0.5 mil less than the nominal minimum gap. The diametral gap in the lower-burnup, low-temperature portion of the rod is less than the minimum specified above. However, the difference between the minimum gap and the maximum expected diametral swelling in the low-burnup portion of the rod is greater than in the highburnup portion. Consequently, the resultant contact probability is less than for the high-burnup location. The effect on the contact probability of truncating the minimum gap distribution may be seen in Figure 30.

The recommended modifications to the fuel element end caps are shown in Figures 32 and 33. The detailed stress analysis of the modified designs has shown that the design for the upper end cap has been significantly improved, and that a large margin of safety is demonstrated for all operating conditions.

The modifications to the lower end, as shown in Figure 32, was made to insure that the ceramic barrier would remain in compression and would not "oilcan" away from the end cap. This was achieved by a slight dishing of the bottom of the cap. The same improvement was automatically achieved with the spherical upper end. The stress levels for the modified lower end cap were essentially identical to those for the previous design. 

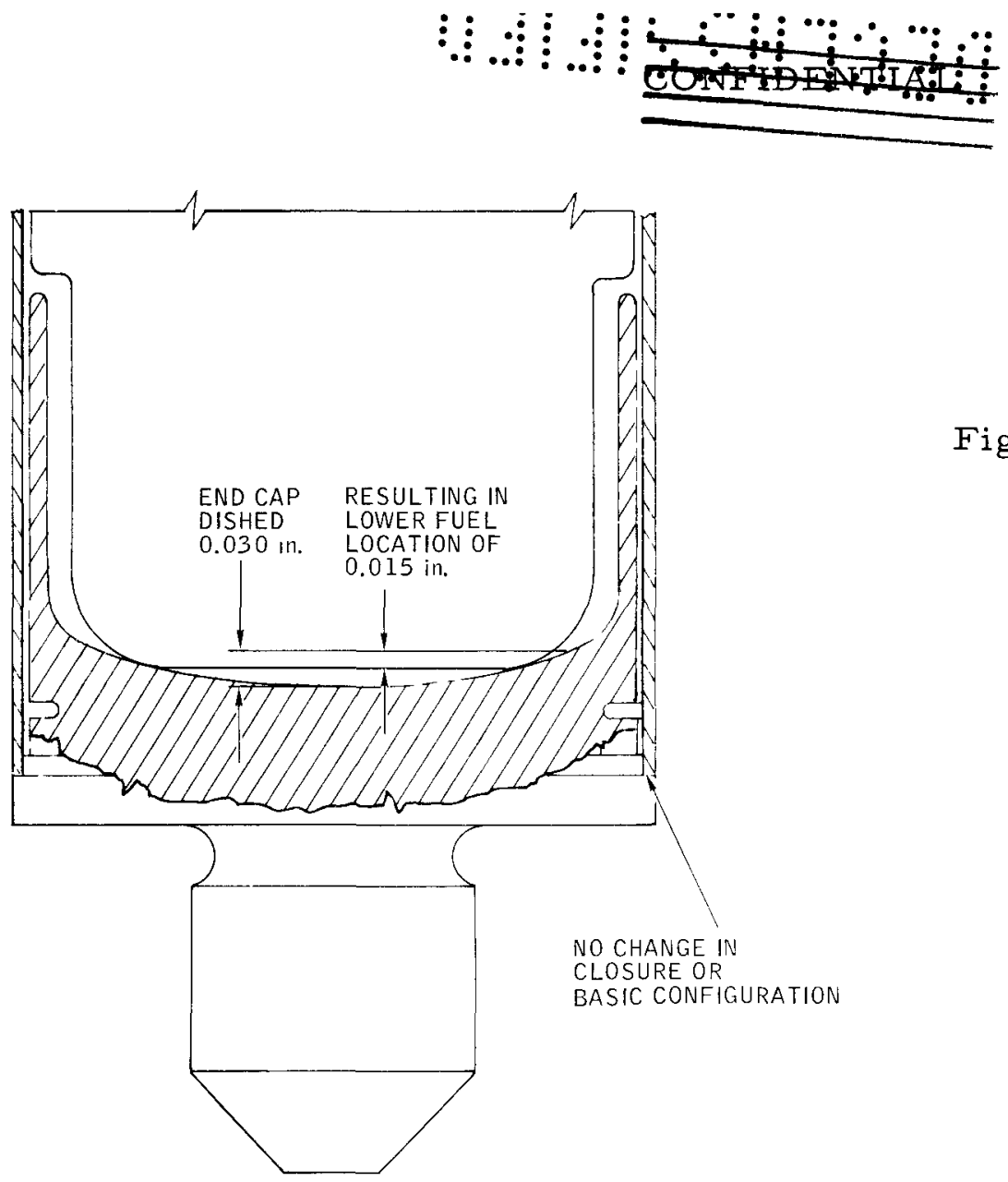

Figure 32. Modified S8DR Fuel Element Lower End Cap

Figure 33. Original and New Reference Upper End Cap Designs

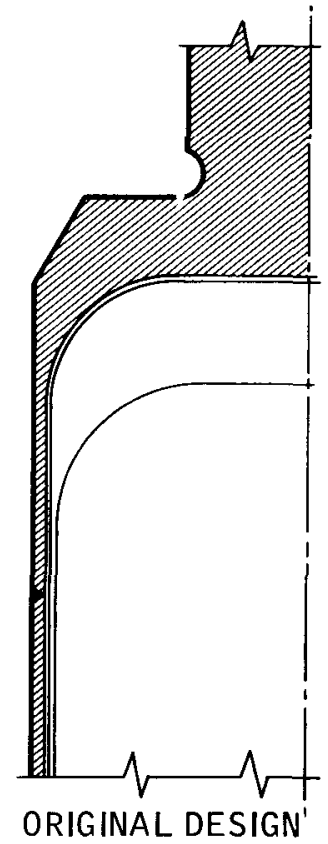

6-22-67 UNC

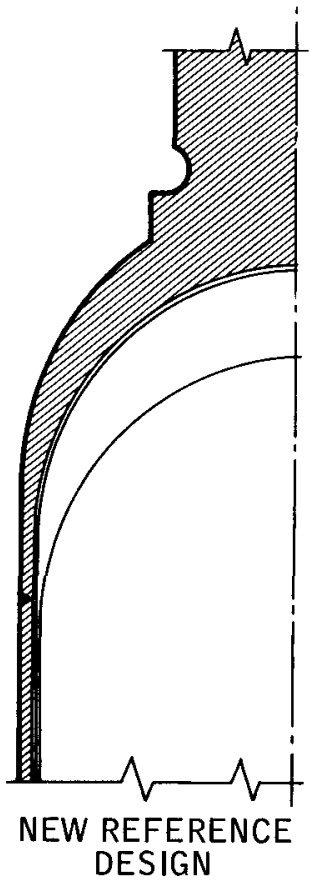

$66-7695-127-114 A$

NAA -SR - 12482

73

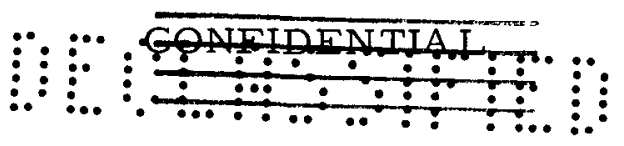


It was recommended that the current 211 -element core concept be retained but that the element-to-element spacing be increased from the previous actual value of 7.4 mils to the previously specified value of 10 mils. This will require shaving of the core vessel ID and the manufacture of new grid plates.

It is further recommended that the coolant flow profile be modified to approach that required for the minimum cladding temperature/maximum life profile. This would be accomplished through the use of a flow distribution ring in the lower plenum and the use of a new flow baffle plate. Hydraulic tests will be required to verify the new baffle plate design.

It is also noted that it is necessary to reduce the operating pressure of the $\mathrm{NaK}$ to 35 psia. This is required to increase the safety factor for the creep collapse of the fuel cladding.

These design modifications will provide the maximum assurance that S8DR will achieve the desired $12,000-\mathrm{hr}$ operation at $600 \mathrm{kwt}$, with $1,300^{\circ} \mathrm{F} \mathrm{NaK}$ outlet temperature, with the minimum perturbations to the previously specified design. 


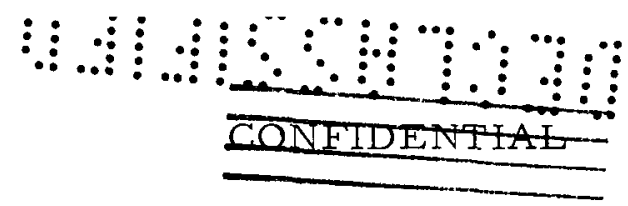

REFERENCES

1. C. E. Johnson, "SNAP 8 Quarterly Progress Report, July-September 1963," NAA-SR-8992, November 15, 1963 (SRD), p 15

2. K. R. Birney and D. J. McGoff, "LOAFER, A Code for Determining Performance Characteristics of SNAP Reactors," NAA-SR-12237, February 1, 1967 (CRD)

3: M. E. Nathan, "FUSAK, A Computing Code for Theoretical Evaluation of SNAP 8 and SNAP 10A Fuel Element Performance During Reactor Operation," NAA-SR-11400, November 1, 1965 (CRD), p 81

4. K. R. Birney, "An Empirical Study of SNAP Reactor Fuel Irradiation Behavior," NAA-SR-12284 (to be published) (CRD)

5. J. R. Miller and D. A. Polak, "Effect of Irradiation on Hydrided ZirconiumUranium Alloy NAA-53 Experiments," NAA-SR-9633, December 30, 1964 (CRD)

6. G. F. Burdi, "SNAP Technology Handbook, Volume II, Hydride Fuels and Cladding," NAA-SR-8617, Vol II, November 15, 1964 (CRD)

7. P. S. Olson, R. C. Courtright, and R. E. Forrester, "In-Pile Behavior of SNAP 8 Experimental Reactor Type Sublength Fuel Elements (NAA-115-1 Experiment)," NAA-SR-11996, November 25, 1966 (SRD)

8. D. G. Mason, "SNAP 8 Progress Report, August-October 1966," NAA-SR-12188, Ja nuary 24, 1967 (CRD)

9. D. G. Mason, "SNAP 8 Progress Report, February-April 1966," NAA-SR-11898, July 15, 1966 (CRD), p 31

10. D. G. Mason, "SNAP 8 Progress Report, May-July 1966," NAA-SR-12068, November 1, 1966 (CRD), p 27

11. L. M. Maki, "Progress Report SNAP Reactor Improvement Program, October-December 1966," NAA-SR-12378 (to be published) (CRD)

12. M. D. O'Neill, "S8ER Wet Critical Configuration Test S8ER-007," NAA-SR-9755 Revised, April 2, 1963 (CRD) 